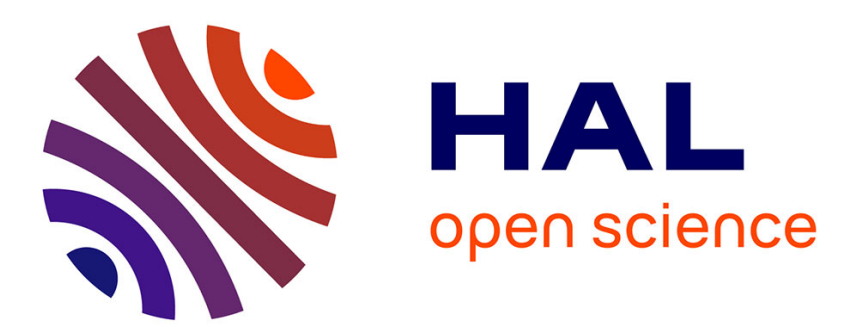

\title{
Boron carbonitride coatings synthesized by LPCVD, structure and properties
}

Géraldine Puyoo, Francis Teyssandier, René Pailler, Christine Labrugère, Georges Chollon

\section{- To cite this version:}

Géraldine Puyoo, Francis Teyssandier, René Pailler, Christine Labrugère, Georges Chollon. Boron carbonitride coatings synthesized by LPCVD, structure and properties. Carbon, 2017, 122, pp.19-46. 10.1016/j.carbon.2017.06.024 . hal-02326454

\section{HAL Id: hal-02326454 https://hal.science/hal-02326454}

Submitted on 25 Oct 2019

HAL is a multi-disciplinary open access archive for the deposit and dissemination of scientific research documents, whether they are published or not. The documents may come from teaching and research institutions in France or abroad, or from public or private research centers.
L'archive ouverte pluridisciplinaire HAL, est destinée au dépôt et à la diffusion de documents scientifiques de niveau recherche, publiés ou non, émanant des établissements d'enseignement et de recherche français ou étrangers, des laboratoires publics ou privés. 


\title{
BORON CARBONITRIDE COATINGS SYNTHESIZED BY LPCVD, STRUCTURE AND PROPERTIES
}

\author{
G. Puyoo $^{1}$, F. Teyssandier ${ }^{1 \dagger}$, R. Pailler ${ }^{1}$, C. Labrugère ${ }^{2}$, G. Chollon ${ }^{1 \ddagger}$ \\ ${ }^{1}$ Laboratoire des Composites Thermostructuraux (UMR 5801 ), \\ CNRS - SAFRAN Ceramics - CEA - University Bordeaux \\ 3, allée de La Boétie, 33600 PESSAC, FRANCE \\ ${ }^{2}$ PLACAMAT (UMS5326), CNRS - University Bordeaux \\ 87, avenue Albert Schweitzer, 33600 PESSAC, FRANCE
}

\begin{abstract}
Thin films of carbon-rich boron carbonitride $(h-B-C-N)$ were prepared by low pressure chemical vapor deposition from $\mathrm{C}_{2} \mathrm{H}_{2}, \mathrm{BCl}_{3}, \mathrm{NH}_{3}$ and $\mathrm{H}_{2}$ mixtures. After an overall investigation of the deposition kinetics and the composition of the solid, four deposition conditions were selected to study in details the structure, the oxidation behavior and the mechanical properties of the deposits. The influence of the gas phase composition on the atomic concentration and the microstructure of the material was first investigated. Carbon rich coatings are turbostratic and highly textured, whereas boron nitride-rich coatings are more disordered and less anisotropic. We examined their oxidation behavior in the range $450^{\circ} \mathrm{C}$ to $700^{\circ} \mathrm{C}$, under both dry and ambient air. The oxidation resistance of the $h-B-C-N$ coatings strongly depends on the deposition temperature and is improved by heat treatments. It is significantly better than that of pyrolytic carbon in dry air but worse in wet air, because of the reactivity of $\mathrm{B}_{2} \mathrm{O}_{3}$ with $\mathrm{H}_{2} \mathrm{O}$. The room temperature stress/strain behavior of unidirectional SiC/SiC composites with $h-B-C-N$ interphases is elastic and damageable as in the case of reference composites having a pyrolytic carbon interphase.
\end{abstract}

Keywords: LPCVD, Boron carbonitride, Structure, Oxidation resistance, Mechanical behavior

\section{1. introduction}

Hexagonal B-C-N materials have become the topic of a large number of researches, since the first reports on the synthesis and characterization of these ternary compounds in the early 1970s.

Most of the researches on B-C-N coatings were aimed at developing new materials for microelectronics or protective coatings against oxidation, corrosion, wear and erosion.

\footnotetext{
${ }^{\dagger}$ Present address: PROMES (UPR8521), CNRS, Tecnosud, Rambla de la thermodynamique, 66100 PERPIGNAN, FRANCE

\$Corresponding author: Tel: +33 5568447 27; E-mail: chollon@lcts.u-bordeaux.fr
} 
Due to the similar crystal structures and similar atom size of graphite and h-BN, the formation of solid solutions in the B-C-N ternary system is expected. Furthermore, the substitution of C-C atomic pairs by isoelectronic B-N pairs satisfies the charge neutrality, as required to get a stable ternary compound. This is the reason why many authors focused on $\mathrm{B}_{1} \mathrm{C}_{\mathrm{x}} \mathrm{N}_{1}$ compositions located on the tie line between $\mathrm{C}$ and $\mathrm{BN}$ in the ternary B-C-N phase diagram. In particular, the electronic properties of hexagonal $\mathrm{BC}_{\mathrm{x}} \mathrm{N}$ compounds are expected to be intermediate between those of a semimetal like graphite, and an insulator like boron nitride. Beyond this specific range of compositions, the synthesis of $\mathrm{B}_{\mathrm{x}} \mathrm{C}_{\mathrm{y}} \mathrm{N}_{\mathrm{z}}$ solid solutions of controlled composition is a way to tune the chemical or physical properties of such materials.

Kosolapova at al. [1] first attempted to synthesize $B_{x} C_{y} N_{z}$ materials by use of a solid-gas reaction between boron and carbon powders under nitrogen or ammonia atmosphere at $1800-2000^{\circ} \mathrm{C}$. Later on, Badzian et al. [2] reported for the first time the synthesis of solid solutions by chemical vapor deposition (CVD) using a gaseous mixture composed of $\mathrm{BCl}_{3}, \mathrm{CCl}_{4}, \mathrm{~N}_{2}$ and $\mathrm{H}_{2}$ at $1900^{\circ} \mathrm{C}$. Their pioneering work paved the way of a long list of attempts aiming at synthesizing and controlling the composition of substitutional B-C-N solid solutions by CVD [3-10]. Even if $\mathrm{B}_{\mathrm{x}} \mathrm{C}_{\mathrm{y}} \mathrm{N}_{\mathrm{z}}$ solid solutions are mainly obtained by CVD, polycrystalline thin films and bulk ceramics have also been synthesized by condensed-phase chemical reactions (solid or liquid) [1,11-13] and polymer pyrolysis [14-18] (Figure 1). Coatings have also been deposited by plasma-enhanced CVD techniques (PECVD) [19-31] such as microwave, glow discharge or magnetron sputtering with various targets. The various microstructures of $\mathrm{B}_{\mathrm{x}} \mathrm{C}_{\mathrm{y}} \mathrm{N}_{\mathrm{z}}$ coatings obtained by CVD and PECVD have recently been compared [32-33].

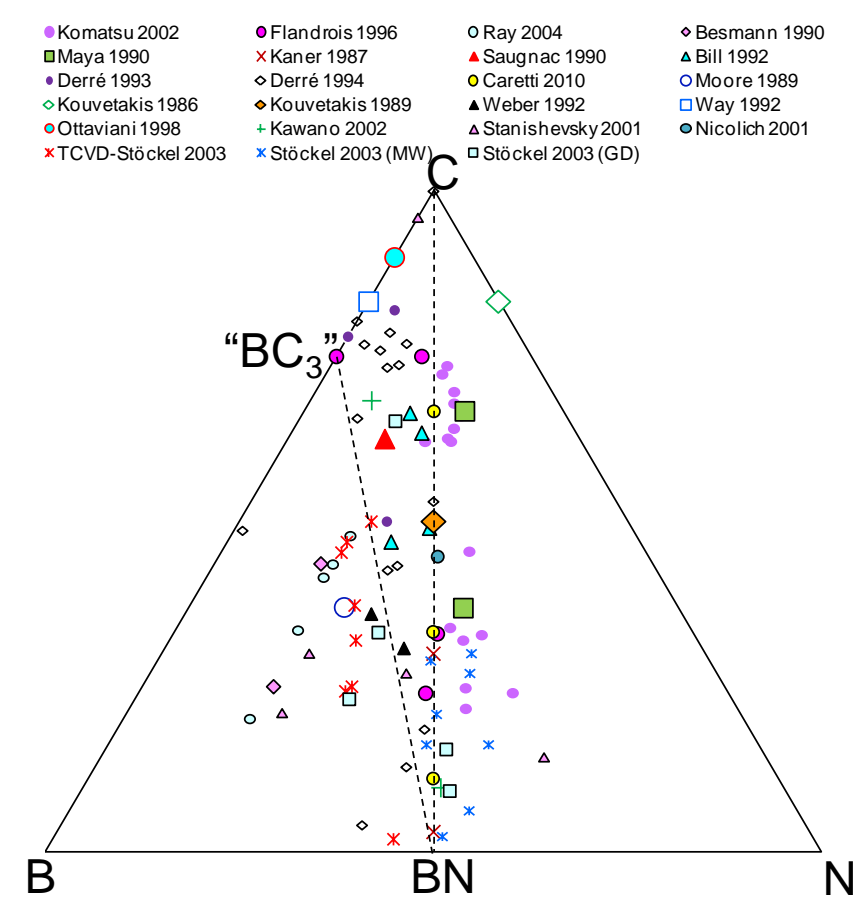

Figure 1: Examples of $\mathrm{B}_{\mathrm{x}} \mathrm{C}_{\mathrm{y}} \mathrm{N}_{\mathrm{z}}$ coating compositions extracted from the literature

CVD is an attractive process as it allows controlling the composition and microstructure of deposited materials, although these two features usually cannot be controlled independently. Previous authors have shown that a wide range of compositions can be attained by CVD starting from a $\mathrm{BCl}_{3}-\mathrm{NH}_{3}-\mathrm{C}_{\mathrm{x}} \mathrm{H}_{\mathrm{y}}$ gas 
mixture, mostly with $\mathrm{H}_{2}$ dilution and $\mathrm{C}_{2} \mathrm{H}_{2}$ as the hydrocarbon. Saugnac et al. [34] deposited crystallized $\mathrm{B}_{\mathrm{x}} \mathrm{C}_{\mathrm{y}} \mathrm{N}_{\mathrm{z}}$ solid solution in the C-rich region of the $\mathrm{B}-\mathrm{C}-\mathrm{N}$ ternary diagram, while the $\mathrm{BN}$-rich coatings were amorphous. Besides, it can be noticed that ion beam-assisted deposition at room temperature leads to the opposite behavior, i.e. to amorphous carbon-rich and crystallized $\mathrm{BN}$-rich materials [31]. The work of Saugnac et al. was further completed by Derre et al. [35] who determined that crystallized $\mathrm{B}_{\mathrm{x}} \mathrm{C}_{\mathrm{y}} \mathrm{N}_{\mathrm{z}}$ solid solutions can be obtained within the whole composition triangle bounded by pure carbon, $\mathrm{BN}$, and $\mathrm{BC}_{3}$.

Since the first attempts to synthesize these materials, their precise structure and thermodynamic stability became a main issue: are these materials true substitutional compounds at the atomic scale or rather simple mixtures of hexagonal BN and carbon? Moore et al. [4] already observed in 1989 that samples deposited in the temperature range $1750-1900^{\circ} \mathrm{C}$ were probably composed of a single-phase mixture of $\mathrm{C}, \mathrm{B}$, and $\mathrm{N}$ atoms, but decomposed into a mixture of $\mathrm{h}-\mathrm{BN}$ and boronated pyrolytic carbon when heat treated at 2500$2700^{\circ} \mathrm{C}$.

Nanotubes are materials of interest to look at in terms of composition homogeneity at the atomic scale. A single-wall nanotube (SWNT) can indeed be considered as a curved graphene monolayer. $\mathrm{B}_{\mathrm{x}} \mathrm{C}_{\mathrm{y}} \mathrm{N}_{\mathrm{z}} \mathrm{SWNT}$ were synthesized by Enouz et al. [36] with a continuous $\mathrm{CO}_{2}$ laser vaporization reactor that was also used to grow C-SWNT or BN-SWNT. The detailed analysis of the atomic composition of SWNT was carried out by means of both HRTEM and nanoelectron energy loss spectroscopy (nanoEELS). Both techniques evidenced that boron and nitrogen atoms co-segregate in a periodic manner in nanodomains embedded in the hexagonal lattice of a graphene layer. Such a segregation phenomenon was theoretically anticipated in the case of the hypothetical $\mathrm{BC}_{2} \mathrm{~N}$ structure. Liu et al. [37], who used pseudopotential local-orbital calculations and Nozaki et al. [38], who applied a semi-empirical method, indeed determined that the lowest total energy structure is obtained by maximizing the number of $\mathrm{C}-\mathrm{C}$ and $\mathrm{B}-\mathrm{N}$ bonds. This can be obtained by the formation of BN-rich nanodomains in substitution for $\mathrm{C}$ atomic pairs in the hexagonal network. Calculations carried out by Nozaki et al. [38] showed the existence of two possible segregated BN patterns of striped or island-type, which may coexist as a quasi-stable state. Using the local density approximation to the density functional theory (DFT), Blase [39] confirmed that the thermodynamic limit of the h- $\mathrm{BC}_{2} \mathrm{~N}$ compound is driven towards segregation. He further showed that in the case of B-doped nanotubes, B atoms segregate in pure $\mathrm{BC}_{3}$ nanodomains. More recently, Ivanovskaya et al. [40] emphasized by DFT study the importance of the description of the $\mathrm{BN} / \mathrm{C}$ boundaries and suggested that $\mathrm{BN} / \mathrm{C}$ interfaces involve $\mathrm{N}-\mathrm{C}$ bonds preferentially.

All these experimental and theoretical results suggest that $\mathrm{B}_{\mathrm{x}} \mathrm{C}_{\mathrm{y}} \mathrm{N}_{\mathrm{z}}$ solid solutions are metastable structures with respect to stable graphite and h-BN compounds. The extended domain of composition that can be achieved by CVD using $\mathrm{NH}_{3}$ gaseous precursor may result from the very high nitrogen activity of this molecule.

In the present work, a large variety of coatings have been prepared by low pressure CVD (LPCVD), following the route proposed by Bartlett and coworkers [41-43], and by Saugnac et al. and Derré et al. [34- 
$35,44]$. They have been all obtained from a $\mathrm{BCl}_{3}, \mathrm{NH}_{3}, \mathrm{C}_{2} \mathrm{H}_{2}$ and $\mathrm{H}_{2}$ gas mixture. Their composition and structure were analyzed respectively by X-ray photoelectron spectroscopy (XPS), transmission electron microscopy and X-ray diffraction. Their oxidation behavior was investigated under dry and ambient air between $450^{\circ} \mathrm{C}$ and $700^{\circ} \mathrm{C}$ and correlated with physicochemical properties.

As pyrolytic carbon (pyrocarbon), h-B-C-N materials have a lamellar structure with strong covalent bonds within the hexagonal layers and weak Van Der Waals-forces between neighboring sheets. This particular structure is ideal for deflecting matrix cracks along the fiber/matrix interface and providing toughness to ceramic matrix composites (CMC) [45]. Furthermore, in boron-substituted pyrocarbons, boron is known to improve the oxidation resistance, compared to pure pyrocarbon and consequently the lifetime of composites in air at high temperature [46-48]. Besides, Saugnac et al. and Derré et al. [49, 44] reported insignificant weight changes at high temperature in dry air of h-B-C-N solid solutions synthesized in conditions close to those of the present study. There are thus substantial reasons to believe that hexagonal B-C-N interphases can be beneficial to the CMC properties. This is what we intend to demonstrate in this paper.

\section{Experimental procedure}

\subsection{A few considerations on the gas phase reactivity}

The gas mixture used to deposit the $\mathrm{B}_{\mathrm{x}} \mathrm{C}_{\mathrm{y}} \mathrm{N}_{\mathrm{z}}$ solid solutions consists of acetylene $\left(\mathrm{C}_{2} \mathrm{H}_{2}\right)$, boron trichloride $\left(\mathrm{BCl}_{3}\right)$, ammonia $\left(\mathrm{NH}_{3}\right)$ and hydrogen $\left(\mathrm{H}_{2}\right)$. This mixture exhibits a high reactivity and its control is of major importance to prevent gas phase nucleation, to obtain homogeneous coatings of the $\mathrm{B}_{\mathrm{x}} \mathrm{C}_{\mathrm{y}} \mathrm{N}_{\mathrm{z}}$ solid solution. The first difficulty is to handle the well-known reaction between $\mathrm{NH}_{3}$ and $\mathrm{HCl}$ that readily leads to ammonium chloride $\left(\mathrm{NH}_{4} \mathrm{Cl}\right)$ at low temperature. $\mathrm{As} \mathrm{HCl}$ is produced by the chemical reactions involved in the deposition process, $\mathrm{NH}_{4} \mathrm{Cl}$ is expected to form and condense downstream in the cold parts of the reactor. To prevent clogging, a minimum temperature of $340^{\circ} \mathrm{C}$, the $\mathrm{NH}_{4} \mathrm{Cl}$ sublimation/decomposition temperature, has to be imposed to the narrow parts at the outlet of the reactor. Another important effect of the high gas phase reactivity is the formation of the Lewis acid-base complex resulting from the reaction between $\mathrm{NH}_{3}$ and $\mathrm{BCl}_{3}$. This reaction is very fast under CVD conditions and is of prime importance in the deposition mechanism of boron nitride. It has been experimentally investigated by McDaniel et al. [50] by the use of a flow-tube reactor connected to a molecular-beam mass-sampling system. These authors probed the gas species present in the hot zone of the reactor and deduced the kinetic parameters of chemical reactions with a numerical approach combining thermokinetics and fluid dynamics. They observed the presence of aminodichloroborane $\mathrm{Cl}_{2} \mathrm{BNH}_{2}$ and diaminochloroborane $\mathrm{ClB}\left(\mathrm{NH}_{2}\right)_{2}$, which are formed by the reaction of $\mathrm{BCl}_{3}$ with two $\mathrm{NH}_{3}$ molecules successively. The gas phase mechanism involved in this chemical system was also investigated by Reinhardt et al. [51] using quantum chemical calculations. They confirm that $\mathrm{BCl}_{3}$ readily forms an adduct with $\mathrm{NH}_{3}$ without any transition state. In contrast, there is a high barrier for the intramolecular elimination of $\mathrm{HCl}$ leading to aminodichloroborane. $\mathrm{Cl}_{2} \mathrm{BNH}_{2}$ can further react with $\mathrm{NH}_{3}$ to form $\mathrm{ClB}\left(\mathrm{NH}_{2}\right)_{2}$, according to a similar reaction path. The formation of triaminoborane by further amination is unfavored since this reaction is endothermic. The authors suggest that aminochloroboranes could also 
react together to yield oligomers in competition with the formation of ammonia adducts. Yet, there is no direct evidence and no thermokinetic reason indicating that these high molecular weight species appear in the gas phase. The high temperature and low pressure applied during deposition are indeed more favorable to smaller species acting as $\mathrm{BN}$ effective precursors.

Strong chemical interactions are also related to the addition of acetylene to the gas phase. During the first experiments carried out in this particular gas feed configuration, a solid complex was found to clog up the line as soon as the two gases were mixed far upstream from the reacting zone. This phenomenon was assigned to the reaction between the electron-rich $\Pi$-bond of $\mathrm{C}_{2} \mathrm{H}_{2}$ and $\mathrm{BCl}_{3}$ to form a Lewis adduct. In addition to the room temperature reactivity of the two gases, other authors suggested that carbon deposition from $\mathrm{C}_{2} \mathrm{H}_{2}$ at high temperature was likely promoted by reactive species formed from the reaction between $\mathrm{BCl}_{3}$ and $\mathrm{NH}_{3}$ [52]. The activated decomposition of $\mathrm{C}_{2} \mathrm{H}_{2}$ was thought to be responsible for the soot formation in the gas phase at high temperature and for long residence time. In order to prevent the reaction between $\mathrm{BCl}_{3}$ and the two other Lewis bases at low temperature and reduce the $\mathrm{C}_{2} \mathrm{H}_{2}$ decomposition at high temperature, the $\mathrm{BCl}_{3} / \mathrm{H}_{2}$ and $\mathrm{NH}_{3} / \mathrm{C}_{2} \mathrm{H}_{2}$ mixtures were driven separately to the reactor with a tube injecting the latter close to -and upstream- of the hot zone. This configuration also allows the reduction by $\mathrm{H}_{2}$ of $\mathrm{BCl}_{3}$ into boron subchlorides, avoiding the adduct formation with $\mathrm{NH}_{3}$ while entering the reactor. Heterogeneous reactions leading to $\mathrm{B}_{\mathrm{x}} \mathrm{C}_{\mathrm{y}} \mathrm{N}_{\mathrm{z}}$ solid solutions are therefore promoted at the expense of homogeneous phenomena.

\subsection{LPCVD reactor}

The reactor (figure 2) consists of a hot-wall silica tube surrounded by a graphite susceptor heated by radiofrequency induction. The graphite susceptor is itself protected from oxidation by a second external silica tube, the gap between the two $\mathrm{SiO}_{2}$ walls being maintained under flowing argon. The temperature of the susceptor is controlled by a thermocouple installed between the central $\mathrm{SiO}_{2}$ tube and the inner graphite wall. Temperature profiles were recorded by shifting a thermocouple along the axis of the reactor, from the bottom of the inductive coil $(x=0)$, where gases enter the hot zone, to the top of the coil $(x=14 \mathrm{~cm})$ at the gas exit. The temperature is maximal at $\mathrm{x}=6 \mathrm{~cm}$ and typically reduced by $10^{\circ} \mathrm{C}$ at $\mathrm{x}=6 \pm 1.5 \mathrm{~cm}$ and $50^{\circ} \mathrm{C}$ at $x=6 \pm 4 \mathrm{~cm}$. The total pressure is regulated with a motorized valve coupled with a Baratron pressure gauge (both from MKS). The initial composition of the gas phase is adjusted by controlling the flow rates of the various gases through mass flow meters (from Brooks Instruments). The total gas flow Q was kept of the order of 440-490 standard $\mathrm{cm}^{3} \mathrm{~min}^{-1}$ ( $\mathrm{sccm}$ ) for the various experiments. At a temperature of $1000^{\circ} \mathrm{C}$ and a total pressure of $5 \mathrm{kPa}, \mathrm{Q}$ corresponds to a residence time of about $25 \mathrm{~ms}$. The purity of the gases is 99.99 mol\% for both $\mathrm{BCl}_{3}$ and $\mathrm{NH}_{3}, 99.7 \mathrm{~mol} \%$ for $\mathrm{C}_{2} \mathrm{H}_{2}$ and $99.9999 \mathrm{~mol} \%$ for $\mathrm{H}_{2}$ (all from Air Liquide). High $\mathrm{BCl}_{3} / \mathrm{NH}_{3}$ ratios (typically 5-10) and variable $\mathrm{C}_{2} \mathrm{H}_{2} / \mathrm{BCl}_{3}$ proportions $(0.25-1.5)$ in the initial gas phase were explored because of a potential combination of effects: the strong reducing nature of $\mathrm{NH}_{3}$ for $\mathrm{BCl}_{3}$, the low heterogeneous reactivity of acetylene and the role of $\mathrm{BCl}_{3}$ in the $\mathrm{C}_{2} \mathrm{H}_{2}$ decomposition. The reactants were 
highly diluted in $\mathrm{H}_{2}$ (approximately 10 times for the total amount of reactants) to promote $\mathrm{BCl}_{3}$ reduction while achieving low residence times.

The coatings were deposited on Nicalon NLM202 SiC-based fibers (with a mean diameter of $14 \mu \mathrm{m}$ ). These fibers are chemically and structurally stable at the deposition temperature. For the first set of experiments, several monofilaments were installed along the whole length of the deposition chamber (from $\mathrm{x}=0-14 \mathrm{~cm}$ ) to examine the influence of both the deposition temperature and the residence time. For the more detailed characterizations as well as the mechanical tests, single fiber $(8 \mathrm{~cm}$ long) were attached on a graphite frame with a carbon-based cement (CM34 from GraphTech) prior to deposition. For the oxidation tests by thermogravimetric analyses (TGA), the coating was deposited on fiber bundles of approximately 500 monofilaments to maximize the reacting surface. The bundles were spread out across the graphite frame to ensure the homogeneity in thickness. Since the total length exposed to gases $(6 \mathrm{~cm})$ was not isothermal, the monofilaments were taken only from the central part of the fiber tows for the tensile tests or the physicochemical analyses.

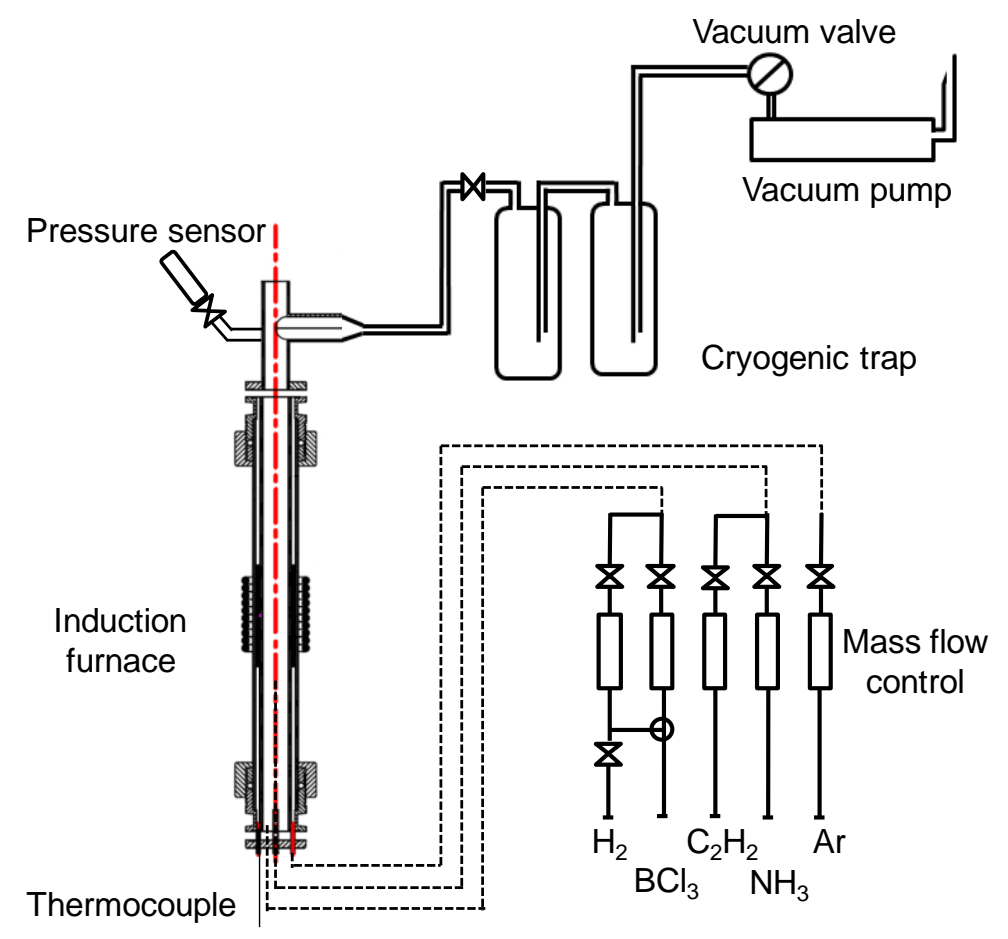

Figure 2: CVD reactor used for the deposition of the $\mathrm{B}_{\mathrm{x}} \mathrm{C}_{\mathrm{y}} \mathrm{N}_{\mathrm{z}}$ coatings

\subsection{Chemical and structural analyses of the $h-B-C-N$ coatings}

The free surface and the failure cross section of the deposits were observed by scanning electron microscopy (SEM Hitachi S4500FEG). Their elemental composition was first examined by energy dispersive X-ray spectrometry (EDS), with the same SEM apparatus. Quantitative analyses were performed in the wavelength-dispersive mode (WDS), by electron probe microanalysis EPMA (Cameca SX 100, operating at $7 \mathrm{kV}$ and 10nA). Pyrolytic carbon, pure boron and silicon nitride $\left(\mathrm{Si}_{3} \mathrm{~N}_{4}\right)$ were used as standards for the $\mathrm{B}$, $\mathrm{C}, \mathrm{N}$ quantification, respectively. The specimens were embedded in epoxy resin and polished prior to the EPMA analyses. Punctual measurements were carried out from the cross sections of coated fibers, in the 
center of a few micrometers-thick coatings. For each CVD condition, a systematic EDS analysis of the surface of the coating was carried out along the axis of the fiber substrate to determine the influence of the residence time on the elemental composition. On the other hand, we investigated the influence of the CVD parameters on the atomic composition of the deposits. For that purpose, the elemental composition was accurately measured by EPMA-WDS, at a given axial position corresponding to the center of the hot zone of the reactor. Accordingly, some discrepancies may be noticed between the compositions measured by EPMA-WDS and the profiles obtained by SEM-EDS. The homogeneity of the composition through the thickness of the coatings was also checked by Auger electron spectroscopy analysis (AES, nanoprobe Auger VG Microlab 310F). The analyses were performed directly from the free surface of coated fibers, simultaneously to argon etching to record the $\mathrm{B}, \mathrm{C}, \mathrm{N}$ and $\mathrm{O}$ atomic profiles.

The structure of the h-B-C-N coatings was examined by X-Ray diffraction (D8 Advance Bruker, $\lambda_{C u-}$ Kal $=0.154056 \mathrm{~nm}$ ). The analyses were carried-out directly from a few micrometer-thick coatings deposited on $\mathrm{SiC}$ fiber tows. A parallel beam/grazing incidence angle $\left(5^{\circ}\right)$ configuration allowed to reduce significantly the influence of the surface roughness and the substrate itself. The average length (Lc) along the $\mathrm{c}$ axis of the coherent domains was calculated using the Scherrer equation:

$$
L c=\frac{K \lambda}{\beta \cos \theta}
$$

Where $K$ is a constant equal to $0.9, \lambda$ is the $\mathrm{X}$-ray wavelength $(\mathrm{Cu}-\mathrm{K} \alpha: 0.15406 \mathrm{~nm})$ and $\beta$ is the experimental width of the 002 diffraction peak, considering that $\beta=\sqrt{\beta_{002}^{2}-\beta_{\text {inst }}^{2}}$, where $\beta_{002}$ is the experimental width and $\beta_{\text {inst }}$ a correction value due to instrumental broadening. $L c$ is only an estimate as the calculation assumes a narrow distribution of the size of the coherent domains.

The structure of the coatings was also investigated by transmission electron microscopy (TEM) (CM30ST Philips, operating at $300 \mathrm{kV}$ ). The coated fibers were embedded in epoxy resin and sandwiched between a silicon wafer and a glass plate. Slices were cut perpendicular to the fibers and mechanically thinned down to $50 \mu \mathrm{m}$. The thin slices were then submitted to $\mathrm{Ar}^{+}$ion beam milling (JEOL IS Ion Slicer, operated at $6 \mathrm{kV}$ ) until the electron transparency of the coating is reached [53].

Raman microspectroscopy analyses (RMS) were achieved in complement of the XRD and TEM structural investigations. Raman spectra were recorded with a Labram HR microspectrometer (from Horiba Jobin Yvon) using a He/Ne laser $(\lambda=632.8 \mathrm{~nm})$. The analyses were made from polished cross sections of the specimens in the punctual mode with a lateral resolution of about $1 \mu \mathrm{m}$. The power of the incident laser beam was kept below $0.5 \mathrm{~mW}$ to avoid local heating of the specimen.

The surface chemistry of the deposits was analyzed by X-ray photoelectron spectroscopy (XPS) (ESCALAB VG 220i-XL spectrometer) using an Al-K $\alpha$ monochromatic RX source $(\mathrm{h} v=1486.6 \mathrm{eV})$. The binding energies were referred to the $\mathrm{Au}_{4 \mathrm{f} 7 / 2}$ peak at $84.0 \mathrm{eV}\left(\mathrm{FWHM}=0.80 \mathrm{eV}\right.$ at a pass energy $\mathrm{E}_{\mathrm{p}}=20 \mathrm{eV}$, was 
acquired only a few days apart from the current $B_{x} C_{y} N_{z}$ spectra). The spectra were acquired at of $E_{p}=40 \mathrm{eV}$ (a compromise value for optimizing spectral resolution and counting statistics). The resolution expected for the binding energy position is $+/-0.1 \mathrm{eV}$ while that of the $\mathrm{Al}-\mathrm{K}_{\alpha}$ line is $0.3 \mathrm{eV}$. The analyses were performed from small bundles of coated fibers. The zone analyzed corresponds to an X-ray spot of about $200 \mu \mathrm{m}$. The XPS spectra were first recorded without sputtering to avoid altering the binding energies. A slight $\mathrm{Ar}^{+}$sputtering was then achieved to remove surface contamination and check the in-depth homogeneity of the elemental composition.

\subsection{Oxidation resistance of the $h-B-C-N$ coatings}

Boron oxide $\left(\mathrm{B}_{2} \mathrm{O}_{3}\right)$ is the only condensed phase that can possibly form during the oxidation of the h-B-C-N coatings. Since $\mathrm{B}_{2} \mathrm{O}_{3}$ is highly reactive to atmospheric moisture, the oxidation tests were carried out in both dry and ambient air for comparison. The oxidation resistance in dry air $\left(\mathrm{N}_{2} / \mathrm{O}_{2}: 80 / 20 \pm 1 \%\right.$, purity: $99.999 \%$, from Air Liquide) was evaluated by thermo-gravimetric analysis (TGA, Setaram TAG 24). Each sample was composed of four specimens of $1 \mathrm{~cm}$ long bundle, containing about $500 \mathrm{SiC}$ monofilaments. The $\mathrm{B}_{\mathrm{x}} \mathrm{C}_{\mathrm{y}} \mathrm{N}_{\mathrm{z}}$ samples were oxidized according to the following temperature sequence: 10 hours at $550^{\circ} \mathrm{C}, 90 \mathrm{~min}$ at $600^{\circ} \mathrm{C}, 30 \mathrm{~min}$ at $650^{\circ} \mathrm{C}$ and $20 \mathrm{~min}$ at $700^{\circ} \mathrm{C}$. The oxidation temperature did not exceed $700^{\circ} \mathrm{C}$ to prevent $\mathrm{B}_{2} \mathrm{O}_{3}$ vaporization. $\mathrm{B}_{2} \mathrm{O}_{3}$ volatilization is indeed negligible below $950^{\circ} \mathrm{C}$ under dry air [54]. The samples were maintained under argon atmosphere during cooling down. For the tests in ambient air, the specimens were simply placed in an open tubular furnace.

\subsection{Mechanical testing of SiC/h-B-C-N/SiC composites}

The ability of $\mathrm{B}_{\mathrm{x}} \mathrm{C}_{\mathrm{y}} \mathrm{N}_{\mathrm{z}}$ films to serve as an interphase in $\mathrm{CMC}$ materials was evaluated by tensile testing microcomposite specimens [55]. The microcomposites were prepared by coating Nicalon NL200 fibers successively with a $150 \mathrm{~nm}$-thick $\mathrm{B}_{\mathrm{x}} \mathrm{C}_{\mathrm{y}} \mathrm{N}_{\mathrm{z}}$ interlayer and a silicon carbide outer coating with a volume fraction of about $45 \%$. Each specimen was mounted on a paper frame to measure its diameter by laser diffraction and align and fix the specimen in the grips of the tensile testing device (the frame was cut afterwards). For each type of interphase, including pyrolytic carbon (serving as a reference), 30 specimens were tested using a gauge length of $10 \mathrm{~mm}$. Longer lengths (25 and $40 \mathrm{~mm}$ ) were occasionally tested in order to calculate the compliance of the system to deduce the strain $\varepsilon$. The stress $\sigma$ was determined from the load and the outer diameter of the micropcomposite. The specimen was monotonically loaded up to failure to determine the limit of the elastic domain $\left(\sigma^{\mathrm{EL}}\right.$ and $\left.\varepsilon^{\mathrm{EL}}\right)$, the Young's modulus $\mathrm{E}$ and the ultimate failure properties $\left(\sigma^{\mathrm{F}}\right.$ and $\left.\varepsilon^{\mathrm{F}}\right)$.

The various batches of microcomposites were submitted to static fatigue (thermal aging under a constant load) in air at $550^{\circ} \mathrm{C}$. The heating and loading bench allowing testing simultaneously 22 specimens (with a $10 \mathrm{~mm}$ gauge length) and the procedure used for the tests are described elsewhere [56]. In order to expose more efficiently the interphase to oxidation, the load applied to each specimen was chosen 10 to $15 \%$ beyond the upper limit of the elastic domain (as identified from the room temperature tensile tests) to induce 
matrix cracking. The lifetime of the microcomposites was measured individually with triggers connected to timers.

\section{Results and discussion}

\subsection{Deposition kinetics and composition of the $\mathrm{B}_{\mathrm{x}} \mathrm{C}_{\mathrm{y}} \mathrm{N}_{\mathrm{z}}$ coatings}

A series of experiments was first performed to identify the influence of the deposition temperature $\mathrm{T}$ and the total pressure $\mathrm{P}$ on the deposition kinetics and the elemental composition of the deposit. The molar fractions in the gas mixture injected in the reactor were fixed at $4 \%, 0.5 \%, 11 \%$ and $84.5 \%$ respectively for $\mathrm{BCl}_{3}$, $\mathrm{NH}_{3}, \mathrm{C}_{2} \mathrm{H}_{2}$, and $\mathrm{H}_{2}\left(\mathrm{BCl}_{3} / \mathrm{NH}_{3}=8\right.$ and $\left.\mathrm{C}_{2} \mathrm{H}_{2} / \mathrm{BCl}_{3}=2.75\right)$, and the total gas flow at 490sccm. For this preliminary study of the $\mathrm{T}$ and $\mathrm{P}$ effects, the deposition rate $\mathrm{R}$ (figure $3 \mathrm{a}$ ) and the elemental composition (as measured by AES, figure 3b) were determined in the center of the hot zone. There is a significant influence of the total pressure on the deposition kinetics and the thermal activation (figure $3 \mathrm{a}$ ), but the effect is also very strong on the composition of the coatings (figure $3 \mathrm{~b}$ ). At $5 \mathrm{kPa}$ and below $980^{\circ} \mathrm{C}$, the deposition rate increases with temperature indicating that the deposition process is controlled by heterogeneous chemical reactions (CR regime). In contrast, at higher temperature, the deposition rate becomes almost independent of temperature according to a process controlled by mass transfer in the gas phase (MT regime). Between 980 and $1050^{\circ} \mathrm{C}$, the decrease of the total pressure results, starting from 5 to $3 \mathrm{kPa}$, in a transition from a MT regime to a first low thermal activation $\mathrm{CR}$ regime (100 and $170 \mathrm{~kJ} \cdot \mathrm{mol}^{-1}$ at 4 and $3 \mathrm{kPa}$, respectively). A second transition is observed from 3 to $1 \mathrm{kPa}$ leading to a more thermally activated CR regime $\left(\approx 500 \mathrm{~kJ} . \mathrm{mol}^{-}\right.$ ${ }^{1}$ ), indicating a change in the deposition mechanism. The deposition rate decreases with the total pressure simultaneously, in particular below $4 \mathrm{kPa}$ in the $\mathrm{CR}$ regimes, due to the higher concentration of reactive species. In the coatings deposited at $1050^{\circ} \mathrm{C}$, the increase of the pressure results in higher boron and nitrogen concentrations and a lower amount of carbon (figure $3 \mathrm{~b}$ ). At $1 \mathrm{kPa}$ and $1050^{\circ} \mathrm{C}$, the deposition rate is low and the coating mainly consists of carbon. At such a low pressure, the deposition process is highly activated by the temperature and essentially controlled by the decomposition of $\mathrm{C}_{2} \mathrm{H}_{2}$ into reactive hydrocarbon species. At $2 \mathrm{kPa}$, the deposition rate increases due to the higher concentration of reactive species, but the deposition mechanism remains unchanged. At $3 \mathrm{kPa}$ and higher pressures, the coatings get gradually enriched in boron and nitrogen through a different deposition mechanism leading to higher deposition rates and a lower activation energy. A very similar T-P dependence has already been noticed for the deposition rate of h-BN from $\mathrm{BCl}_{3}-\mathrm{NH}_{3}-\mathrm{H}_{2}$ mixtures [57]. 

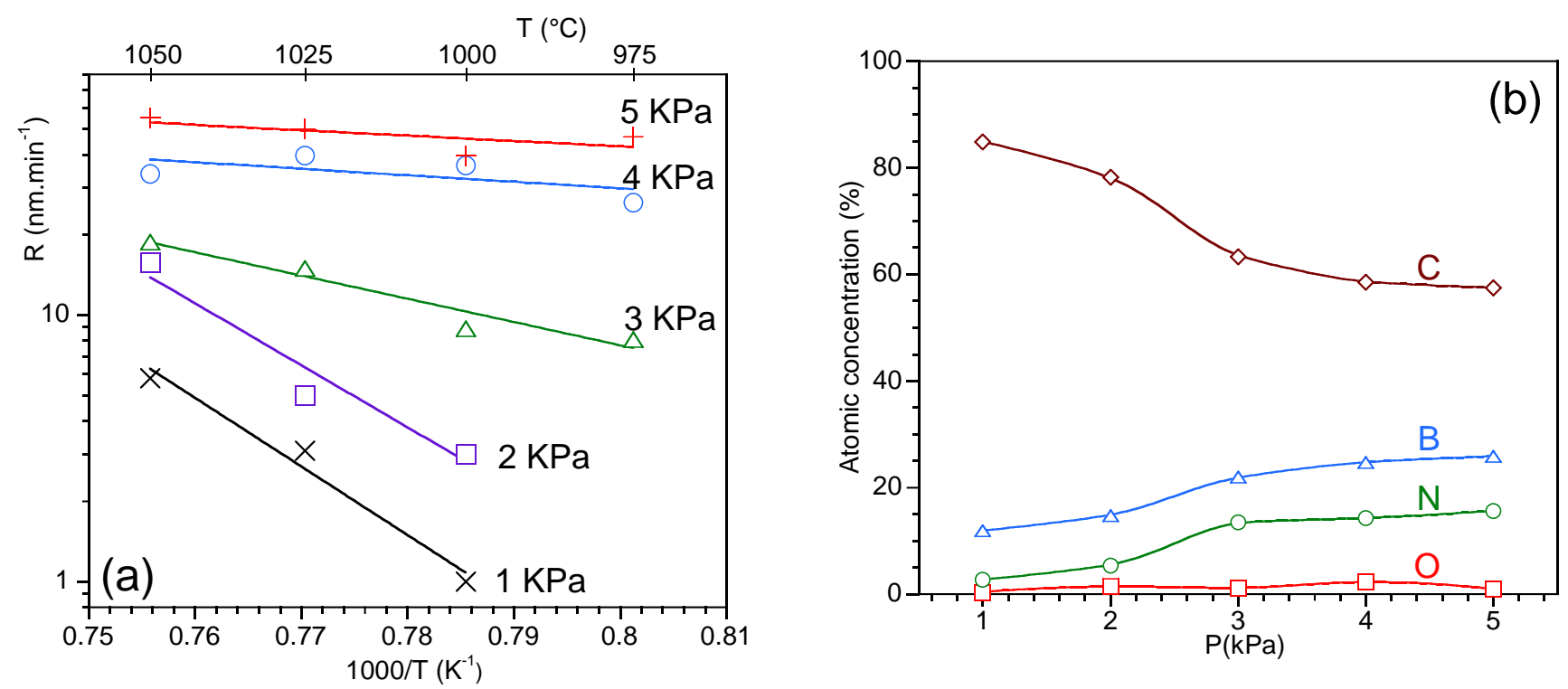

Figure 3: Deposition rate $\mathrm{R}$ as a function of temperature and total pressure (a) and atomic concentration (as measured by AES) of coatings deposited at $1050^{\circ} \mathrm{C}$ as a function of total pressure (b)

The composition and the thickness of the coatings were measured by SEM-EDS along the whole length of the reactor for a deposition temperature of $1025^{\circ} \mathrm{C}$ and two distinct values of the total pressure: $2 \mathrm{kPa}$ (figure 4a) and $4 \mathrm{kPa}$ (figure 4b). In both cases the deposit is almost oxygen free except near the exit of the reactor. The temperature at this position of the reactor is well below that of the central hot zone. The unstable solid deposited reacts with oxygen after cooling when exposed to the ambient air. At $2 \mathrm{kPa}$, the deposits are thin, carbon rich and do not include nitrogen at the entrance of the hot zone. The deposition rate and the amounts of $\mathrm{B}$ and $\mathrm{N}$ both increase rapidly when going further on, while the residence time increases. The coating is almost composed of pure BN near the end the hot zone.
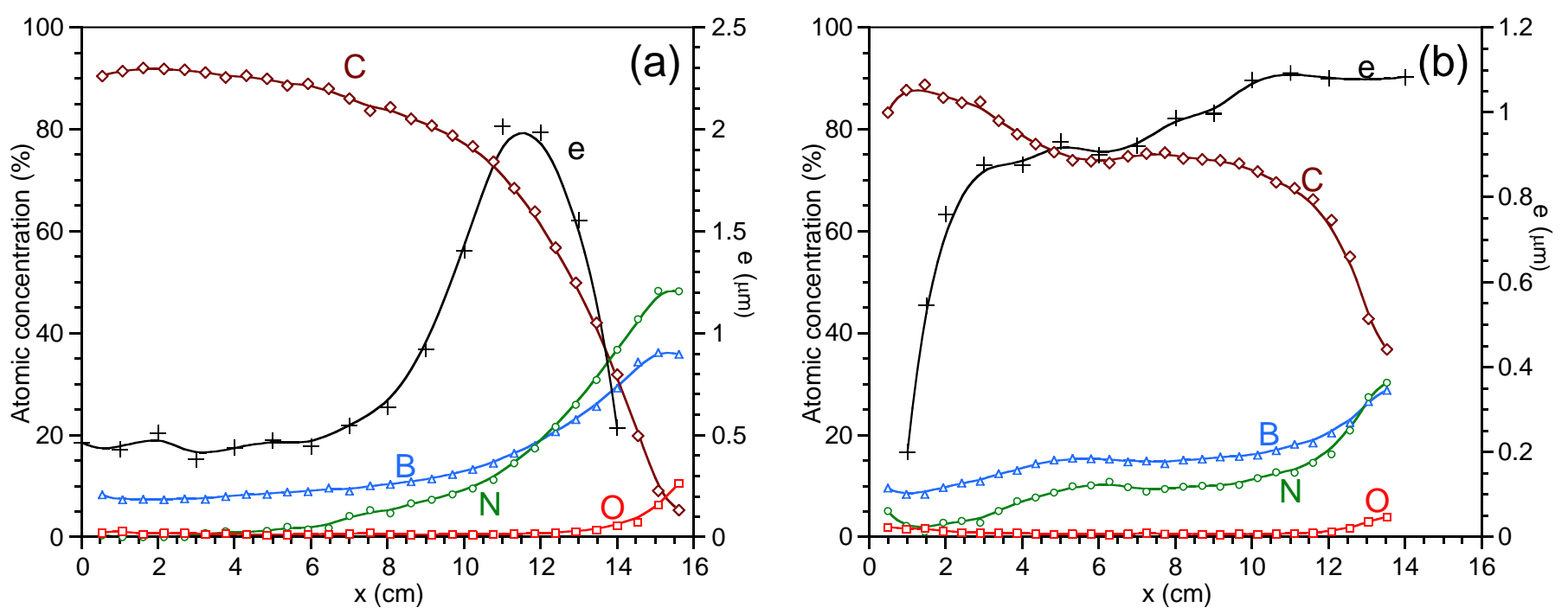

Figure 4: Atomic concentration (as measured by EDS) and thickness profiles as a function of the position $\mathrm{x}$ along the reactor. $\mathrm{x}=0$ corresponds to the gas inlet at reactor bottom: (a) $2 \mathrm{kPa}$, (b) $4 \mathrm{kPa}\left(\mathrm{T}=1050^{\circ} \mathrm{C}\right.$, $\left.\mathrm{Q}_{\mathrm{tot}}=490 \mathrm{sccm}\right)$ 
The composition profiles are entirely different at $4 \mathrm{kPa}$. The deposition rates of $\mathrm{B}$ and $\mathrm{N}$ are enhanced from the very entrance of the hot zone, and the composition and thickness gradients are consequently both significantly reduced (figure $4 \mathrm{~b}$ ). In agreement with figure $3 \mathrm{a}$, the reactivity of the $\mathrm{BCl}_{3}-\mathrm{NH}_{3}$ system and thus, the $\mathrm{B}$ and $\mathrm{N}$ deposition rate, are both improved with an increase of the total pressure. These conditions allow the deposition of the $\mathrm{C}, \mathrm{B}$ and $\mathrm{N}$ elements at rates that are compatible with the formation of the $\mathrm{B}_{\mathrm{x}} \mathrm{C}_{\mathrm{y}} \mathrm{N}_{\mathrm{z}}$ solid solution and all relatively constant versus the residence time.

In a next step, the temperature and the total pressure were both maintained constant at respectively $1025^{\circ} \mathrm{C}$ and $4 \mathrm{kPa}$, and the partial pressures of the various precursors were varied independently to study their influence on the deposition rate and the elemental composition of the resulting coatings. More precisely, the influence of the ammonia flow rate $\mathrm{Q}_{\mathrm{NH} 3}$ was investigated for several values of the acetylene flow rate $\mathrm{Q}_{\mathrm{C} 2 \mathrm{H} 2}$, the $\mathrm{H}_{2}$ and $\mathrm{BCl}_{3}$ flow rates being both constant and the total gas flow rate (and thus the residence time) remaining nearly unchanged (table 1). For a given value of $\mathrm{Q}_{\mathrm{C} 2 \mathrm{H} 2}$, the increase of $\mathrm{Q}_{\mathrm{NH} 3}$ results apparently in the substitution of carbon by $\mathrm{BN}$ in the overall composition of the coatings (figure 5). This result suggests that, although $\mathrm{BCl}_{3}$ and $\mathrm{NH}_{3}$ are independent precursors of respectively boron and nitrogen, they jointly contribute to the composition of the $\mathrm{B}_{\mathrm{x}} \mathrm{C}_{\mathrm{y}} \mathrm{N}_{\mathrm{z}}$ coatings through the formation of $\mathrm{sp}^{2} \mathrm{~B}-\mathrm{N}$ bonds in the solid. Indeed, gaseous species bearing both $\mathrm{B}$ and $\mathrm{N}$ atoms could be formed directly from gas phase reactions as discussed in the previous section. Since $\mathrm{BCl}_{3}$ is in large excess in the initial gas mixture, an increasing amount of ammonia is likely to promote reactions between $\mathrm{BCl}_{3}$ and $\mathrm{NH}_{3}$ to form potential $\mathrm{BN}$ gas precursors such as $\mathrm{Cl}_{2} \mathrm{BNH}_{2}$. The $\mathrm{B}_{\mathrm{x}} \mathrm{C}_{\mathrm{y}} \mathrm{N}_{\mathrm{z}}$ compositions are close but noticeably out of the $\mathrm{C}$ - $\mathrm{BN}$ tie line on the B-rich side of the ternary B-C-N phase diagram (figure 5). This suggests the formation, probably by surface reactions, of $\mathrm{sp}^{2}$-hybridized $\mathrm{B}-\mathrm{C}$ and C-C bonds in parallel to the $\mathrm{B}-\mathrm{N}$ bonds of the $\mathrm{B}_{\mathrm{x}} \mathrm{C}_{\mathrm{y}} \mathrm{N}_{\mathrm{z}}$ coating. Only a few details are available in the literature dealing with homogeneous or heterogeneous reactions involved in the growth mechanism of hexagonal C-B (i.e. $\mathrm{sp}^{2}$ boronated carbon) coatings from $\mathrm{BCl}_{3}$ and $\mathrm{C}_{2} \mathrm{H}_{2}$. Yet, one can assume from other studies on the CVD of boron carbide [58] that species bearing both $\mathrm{B}$ and $\mathrm{C}$ atoms are unlikely to form in significant amounts in the gas phase and serve as effective precursors of $\mathrm{B}_{\mathrm{x}} \mathrm{C}_{\mathrm{y}} \mathrm{N}_{\mathrm{z}}$ coatings.

\begin{tabular}{|c|c|c|c|c|}
\hline $\mathrm{Q}_{\mathrm{C} 2 \mathrm{H} 2}(\mathrm{sccm})$ & 28 & 10 & 7.5 & 5 \\
\hline $\mathrm{Q}_{\mathrm{BC} 13}(\mathrm{sccm})$ & 20 & 20 & 20 & 20 \\
\hline $\mathrm{Q}_{\mathrm{NH} 3}(\mathrm{sccm})$ & $2.4-2.8$ & $1.2-3.6$ & $3.0-3.6$ & $2.8-4.0$ \\
\hline $\mathrm{Q}_{\mathrm{H} 2}(\mathrm{sccm})$ & 415 & 415 & 415 & 415 \\
\hline$\tau_{\mathrm{R}}(\mathrm{ms})$ & 21 & 22 & 22 & 22 \\
\hline
\end{tabular}

Table 1: Gas flow rates applied for the $\mathrm{CVD}$ of $\mathrm{B}_{\mathrm{x}} \mathrm{C}_{\mathrm{y}} \mathrm{N}_{\mathrm{z}}$ coatings $\left(\mathrm{T}=1025^{\circ} \mathrm{C}, \mathrm{P}=4 \mathrm{kPa}\right.$, see elemental composition in figure 5) 


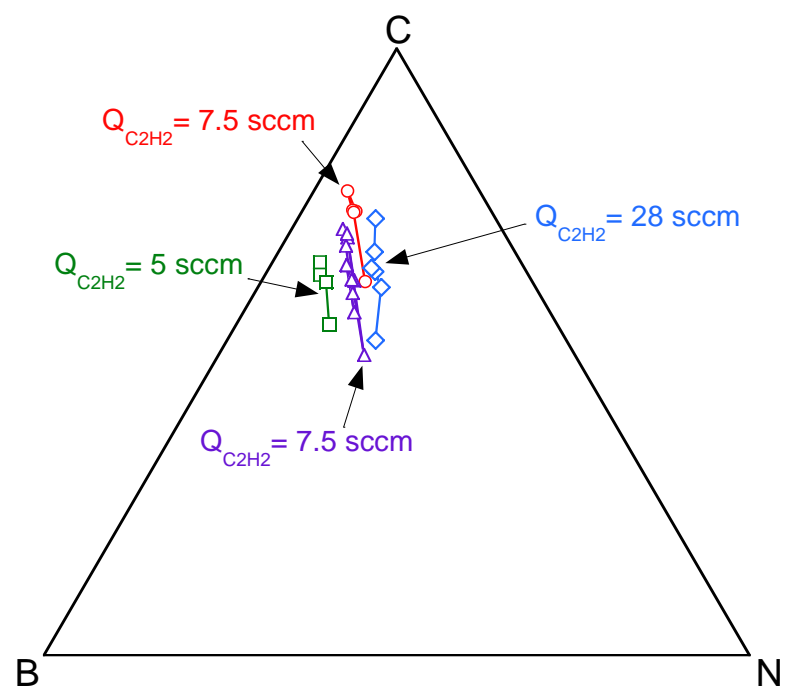

Figure 5: Influence of the initial composition of the gas phase on the atomic concentration of the coatings (see Table 1) $\left(\mathrm{P}=4 \mathrm{kPa}, \mathrm{T}=1050^{\circ} \mathrm{C}, \mathrm{Q}_{\mathrm{tot}}=490 \mathrm{sccm}\right)$

\subsection{Selection of a set of $B_{x} C_{y} N_{z}$ coatings}

Four coatings (S1, S2, S3 and S4) of different elemental compositions and deposited from different initial gas mixtures, were selected for more detailed characterizations. The deposition temperature of $1025{ }^{\circ} \mathrm{C}$ was chosen high enough to obtain a highly anisotropic coating, but sufficiently low to avoid any thermal degradation of the fibers that could lead to a drop of their mechanical strength. The total pressure was fixed at $4 \mathrm{kPa}$ and the total flow rate was maintained close $450 \mathrm{sccm}$ for the entire set of experiments. These conditions indeed lead to homogeneous thickness and composition (figure 4) along the 50-60 millimeter lengths of the fiber substrate needed for the mechanical tests (see section 2.5).

The influence of the initial composition of the gas phase on the elemental composition of the deposits is highlighted in figure 6 on two $\mathrm{BCl}_{3}-\mathrm{C}_{2} \mathrm{H}_{2}-\mathrm{NH}_{3}$ (a) and $\mathrm{B}-\mathrm{C}-\mathrm{N}$ (b) ternary plots. The respective gas flows and atomic concentrations are gathered in table 2 (the $\mathrm{H}_{2}$ flow was maintained constant at $415 \mathrm{sccm}$ for all runs). As well as for previous deposits, the oxygen concentration in these four coatings is lower than 1 at.\%, the detection limit of EPMA-WDS. Coating S2, which is prepared with the lowest proportion of $\mathrm{NH}_{3}$ in the gas phase, contains the highest carbon concentration and the closest composition to the C-BN tie line. As expected, the $\mathrm{C}$ concentration decreases significantly with the initial $\mathrm{C}_{2} \mathrm{H}_{2}$ ratio in the gas phase. Coating $\mathrm{S} 4$, obtained with the lowest proportion of $\mathrm{C}_{2} \mathrm{H}_{2}$, displays indeed the lowest $\mathrm{C}$ content and the highest $\mathrm{B}$ and $\mathrm{N}$ concentrations. The two diagrams confirm besides that a large $\mathrm{BCl}_{3} / \mathrm{NH}_{3}$ ratio is also required in the initial gas phase to reach significant contents of $\mathrm{B}$ and $\mathrm{N}$ in the deposits. This result illustrates the dual role of $\mathrm{BCl}_{3}$ in the deposition process of $\mathrm{B}_{\mathrm{x}} \mathrm{C}_{\mathrm{y}} \mathrm{N}_{\mathrm{z}}$, i.e. the reaction with $\mathrm{C}_{2} \mathrm{H}_{2}$ required for the deposition of $\mathrm{C}$ and the reaction with $\mathrm{NH}_{3}$ (through the formation of gas intermediates) leading to the deposition of $\mathrm{B}$ and $\mathrm{N}$.

The deposition rate $(\mathrm{R})$ of the S1-S4 coatings was also evaluated by direct SEM thickness measurements. $\mathrm{R}$ varies only moderately with the initial composition of the gas phase. Higher $\mathrm{H}_{2} / \mathrm{BCl}_{3}$ ratios, leading to 
higher carbon contents, results in a slight inhibition of the deposition rate: $\mathrm{R}$ indeed decreases from $3.8 \mu \mathrm{m} / \mathrm{h}$ for $\mathrm{S} 4$ to $2.9 \mu \mathrm{m} / \mathrm{h}$ for $\mathrm{S} 2$.
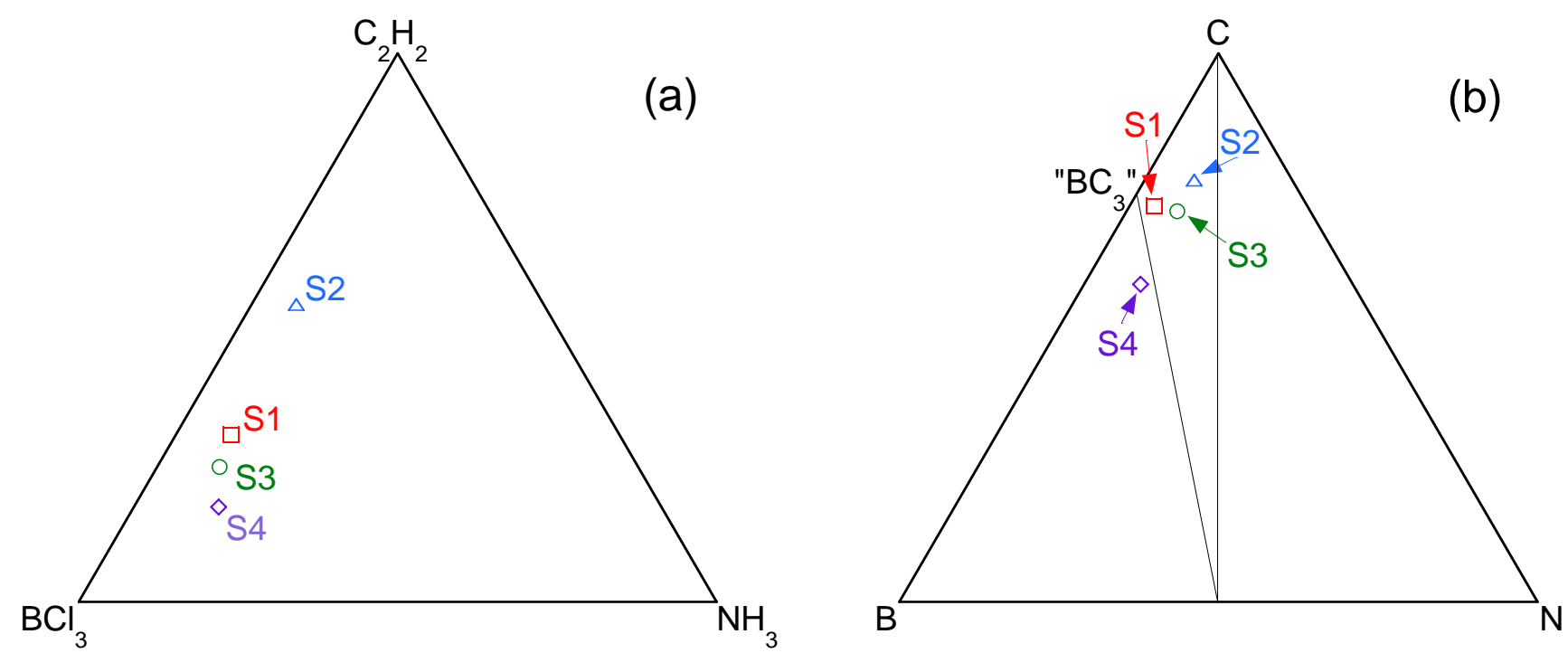

Figure 6: influence of the initial composition of the gas phase (a) on the atomic concentration of the $B_{x} C_{y} N_{z}$ coatings (see Table 2), (b) $\left(\mathrm{P}=4 \mathrm{kPa}, \mathrm{T}=1050^{\circ} \mathrm{C}, \mathrm{Q}_{\mathrm{H} 2}=415 \mathrm{sccm}\right)$

3.3. Physicochemical characterization of the $\mathrm{S} 1-\mathrm{S} 4 \mathrm{~B}_{\mathrm{x}} \mathrm{C}_{\mathrm{y}} \mathrm{N}_{\mathrm{z}}$ coatings and comparison with pyrocarbon reference

As a matter of comparison, a pyrolytic carbon coating was synthesized in the same CVD reactor and submitted to the same investigations as the $\mathrm{B}_{\mathrm{x}} \mathrm{C}_{\mathrm{y}} \mathrm{N}_{\mathrm{z}}$ coatings, except for Raman microspectroscopy analyses. This reference specimen, simply referred to as $\mathrm{PyC}$ in the following sections, was deposited at $1025^{\circ} \mathrm{C}$ and 5 $\mathrm{kPa}$ from a $\mathrm{C}_{3} \mathrm{H}_{8}-\mathrm{H}_{2}$ mixture (1/1 in volume). In the particular case of RMS analyses, the $\mathrm{B}_{\mathrm{x}} \mathrm{C}_{\mathrm{y}} \mathrm{N}_{\mathrm{z}}$ coatings were compared to a rough laminar pyrocarbon (RL-PyC) [59].

\begin{tabular}{|c|c|c|c|c|c|c|}
\hline & $\mathrm{Q}_{\mathrm{BC} 3}(\mathrm{sccm})$ & $\mathrm{Q}_{\mathrm{C} 2 \mathrm{H} 2}(\mathrm{sccm})$ & $\mathrm{Q}_{\mathrm{NH} 3}(\mathrm{sccm})$ & $\mathrm{x}_{\mathrm{B}}(\mathrm{at} . \%)$ & $\mathrm{x}_{\mathrm{C}}(\mathrm{at} . \%)$ & $\mathrm{x}_{\mathrm{N}}(\mathrm{at} . \%)$ \\
\hline $\mathrm{S} 1$ & 20 & 10 & 2.8 & 24.0 & 72.2 & 3.8 \\
\hline $\mathrm{S} 2$ & 20 & 28 & 3.6 & 15.4 & 76.9 & 7.7 \\
\hline S3 & 20 & 7.5 & 3 & 20.9 & 71.2 & 7.9 \\
\hline S4 & 20 & 5 & 3.8 & 33.1 & 58.0 & 8.8 \\
\hline
\end{tabular}

Table 2: Gas flow rates applied for the CVD of four $\mathrm{B}_{\mathrm{x}} \mathrm{C}_{\mathrm{y}} \mathrm{N}_{\mathrm{z}}$ coatings (S1-S4) deposited in different gas phase conditions $\left(\mathrm{T}=1025^{\circ} \mathrm{C}, \mathrm{P}=4 \mathrm{kPa}, \mathrm{Q}_{\mathrm{H} 2}=415 \mathrm{sccm}\right)$ and respective atomic concentration $\mathrm{x}_{\mathrm{i}}$, as measured by EPMA-WDS

\section{- 3.3.1 Morphological analyses}

SEM observations were carried out from fractured cross sections of the coatings. Some delamination is visible between the fiber and the coating (figure 7) that probably appeared during the intentional fracture. This indication of poor interfacial strength, which is often encountered in the case of pure BN interphases, is 
probably due to the presence of a thin silica interlayer [60]. On the other hand, no transverse cracks that would affect the oxidation resistance could be detected from the outer surface of the $\mathrm{B}_{\mathrm{x}} \mathrm{C}_{\mathrm{y}} \mathrm{N}_{\mathrm{z}}$ coatings.

Significant disparities in the microstructure can be evidenced when comparing the different coatings (figure 7). The typical layered structure of pyrolytic carbon is only observed in the case of S1 and S2, the S3 and S4 coatings exhibiting instead a rather granular morphology. This mere feature suggests that S1 and S2 would be more appropriate for crack deflection, from mode I to mode II, than the two other coatings.
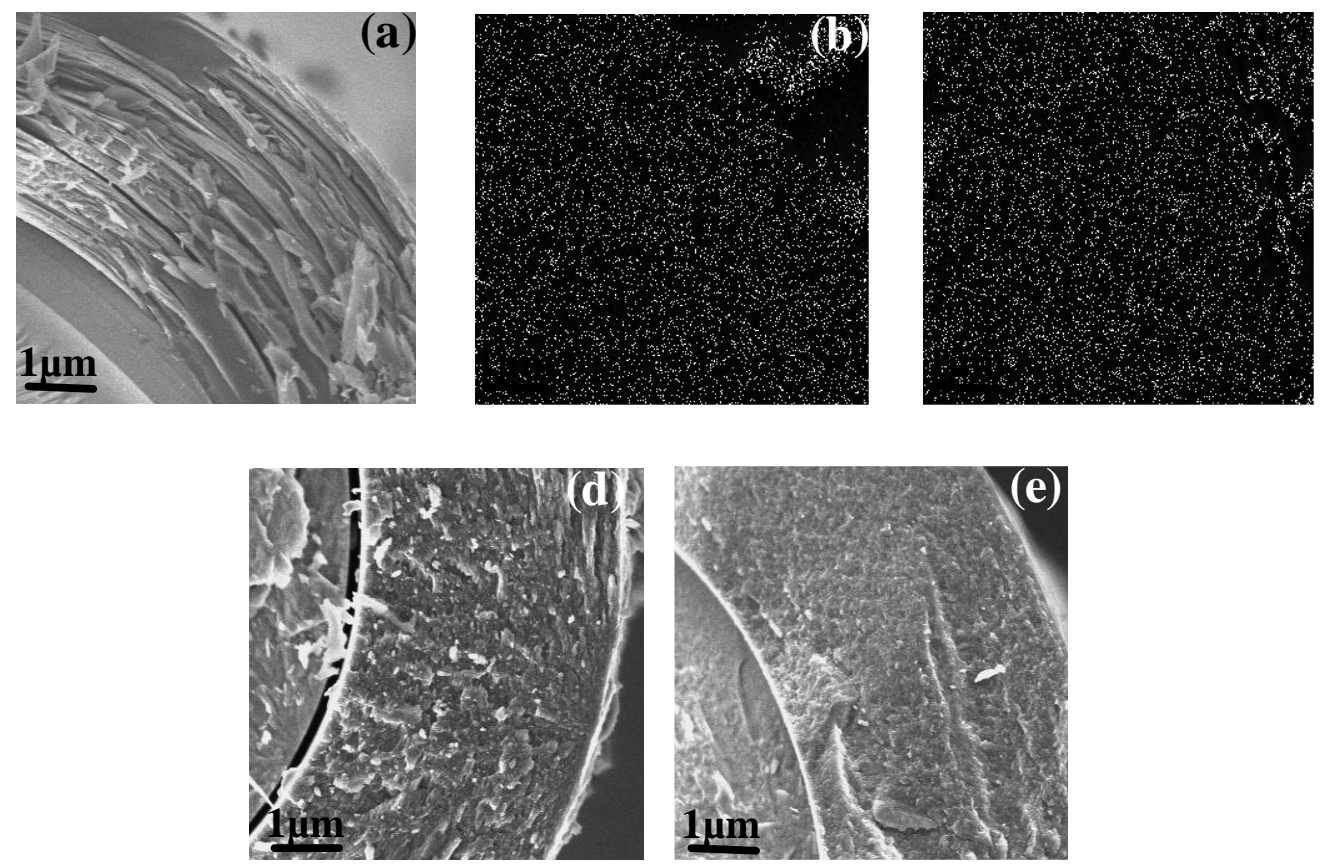

Figure 7: Cross section of the (a) pyrocarbon and $\mathrm{B}_{\mathrm{x}} \mathrm{C}_{\mathrm{y}} \mathrm{N}_{\mathrm{z}}$ coatings, deposited on SiC fibers: (b) $\mathrm{S} 1$, (c) $\mathrm{S} 2$, (d) S3 and (e) S4

\section{- 3.3.2 Structural and textural analyses}

The structure and the anisotropy of the $\mathrm{B}_{\mathrm{x}} \mathrm{C}_{\mathrm{y}} \mathrm{N}_{\mathrm{z}}$ coatings were investigated at various scales by polarizedlight microscopy (PLM), transmission electron microscopy (TEM), Raman microspectroscopy (RMS) and $\mathrm{X}$-ray diffraction (XRD). These techniques are often employed for the characterization of pyrolytic carbons [61-63] but they are also suited to other lamellar materials with hexagonal structures. The term microtexture generally used to describe pyrocarbons is typically multiscale as it includes the curvature and length of the individual hexagonal sheets, their stacking into coherent domains and their preferential orientation (or anisotropy) with respect to the growth direction. The anisotropy of the coatings is a relatively long range property. It can be characterized at the 1-10 $\mu \mathrm{m}$ scale by the extinction angle $A_{e}$ and the intensity ratio $R_{A}$, determined respectively by PLM and polarized RMS. In the case of pyrocarbon, $A_{e}$ and $R_{A}$ both increase with the anisotropy [63-66]. The preferential orientation of the carbon layers can also be assessed at various submicrometer scales from the orientation angle OA of the 002 arc on the SAED pattern. The misorientation distribution of the layers (OA) decreases when the anisotropy is improved [65-66].

Structural features at shorter range are accessible by XRD, TEM and RMS. These techniques allow respectively the quantification of the coherent domains (i.e. the size of coherent domains along the c axis Lc 
and the 002 interlayer distance $\mathrm{d}_{002}$ ), the direct examination of the atomic layers from the 002 lattice fringe and the indirect assessment of the density of in-plane defects from the width of the Raman D band WD $_{\mathrm{D}}$ [59]. It is indeed important to recall that, for the main part, the Raman features of hexagonal carbon and BN (G, $\mathrm{D}, \mathrm{D}^{\prime}$...) correspond to in-plane vibrations.

The $A_{e}$ measurements were carried out in the same configuration on the reference $P y C$ and $B_{x} C_{y} N_{z}$ coatings. S1 exhibits a slightly higher anisotropy than S2, which is itself much more anisotropic than S3 and S4. The $\mathrm{B}_{\mathrm{x}} \mathrm{C}_{\mathrm{y}} \mathrm{N}_{\mathrm{z}}$ coatings are all less textured than the reference PyC coating. The SAED patterns used for the assessment of OA were recorded with a $100 \mu \mathrm{m}$ selector diaphragm. According to the OA-based classification proposed by Reznik-Hüttinger [65], the S1 coating is close to the high-textured category, while $\mathrm{S} 2$ is medium-textured and S4 very low-textured (table 3).

\begin{tabular}{|c|c|c|c|c|c|}
\hline & PyC & S1 & S2 & S3 & S4 \\
\hline EA $\left(^{\circ}\right)$ & 16 & 10 & 8 & n.m. & n.m. \\
\hline OA $\left(^{\circ}\right)$ & n.d. & 55 & 68 & n.d. & 135 \\
\hline
\end{tabular}

Table 3: Extinction angles $\left(\mathrm{A}_{\mathrm{e}}\right)$, as measured by polarized light microscopy and orientation angles (OA), as measured by TEM from the 002 arc on the SAED diffraction pattern: comparison of the PyC and S1-S4 $\mathrm{B}_{\mathrm{x}} \mathrm{C}_{\mathrm{y}} \mathrm{N}_{\mathrm{z}}$ coatings (n.d.: not determined, n.m.: not measurable).

The 002 lattice fringe micrographs and related SAED patterns are in good agreement with the $\mathrm{A}_{\mathrm{e}}$ and OA measurements and reveal further differences in the structure at the atomic scale of the various $\mathrm{B}_{\mathrm{x}} \mathrm{C}_{\mathrm{y}} \mathrm{N}_{\mathrm{z}}$ coatings (figure 8). 

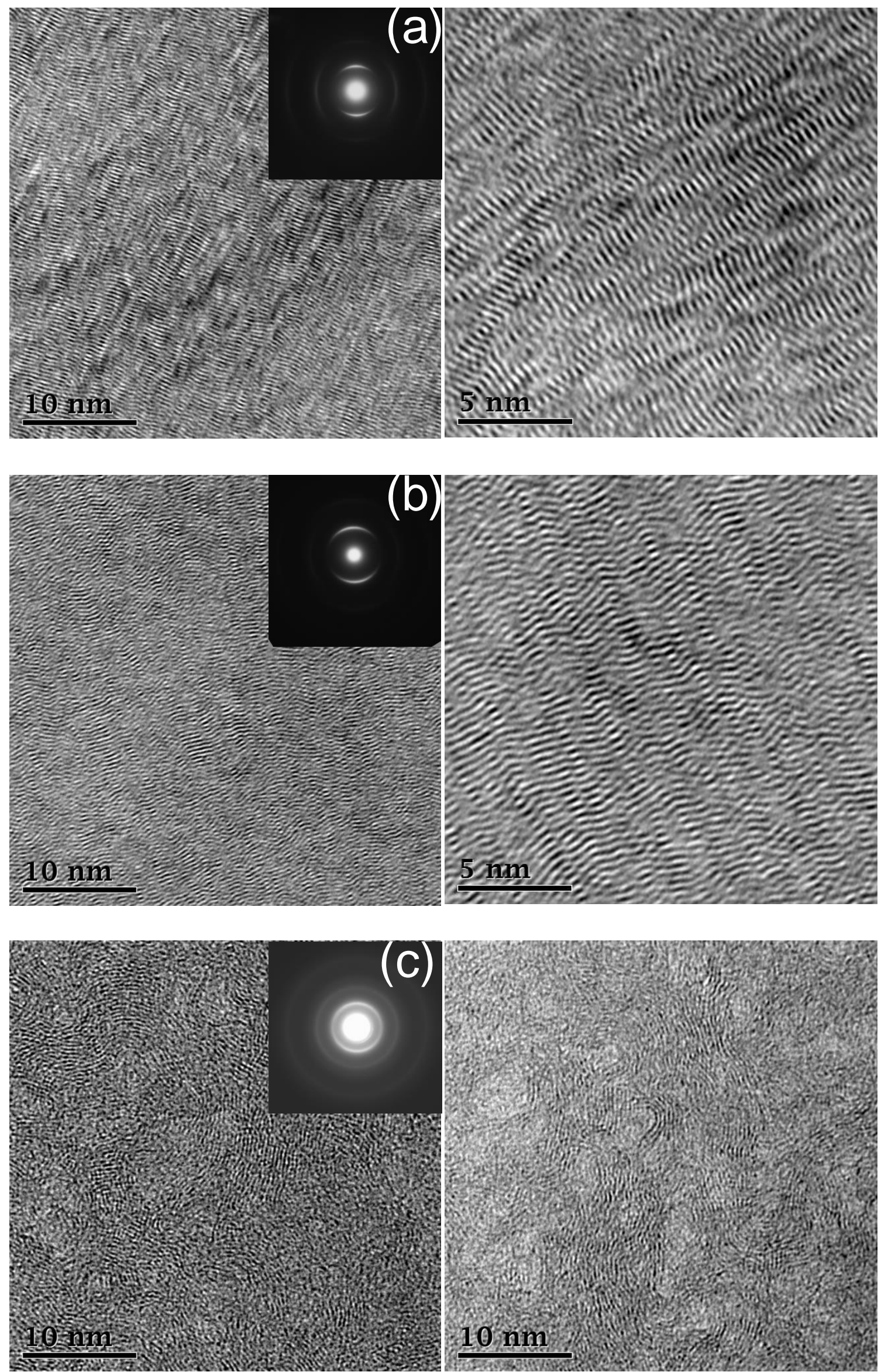

Figure 8: HR-TEM and diffraction patterns of (a) S1, (b) S2 and (c) S4 coatings 
The fringes are well contrasted revealing slightly larger coherent domains in S1 than in S2. These carbon rich coatings both exhibit a clear laminar texture with a marked preferential orientation of 002 layers. The increase in the $\mathrm{B}$ and $\mathrm{N}$ contents results in a decrease of anisotropy as well as major changes in the microtexture. This is obvious from the HRTEM micrograph of the S4 coating showing highly distorted and tangled 002 layers. These strong curvatures are probably associated with the presence of in-plane defects such as 5 or 7 membered rings or vacancies, as observed in pyrocarbon [67]. The curved layers surround nano-domains of porosity or amorphous material and are present in larger proportions in S4 than in S1 or S2.

The Raman spectra of the reference RL-PyC and the various $B_{x} C_{y} N_{z}$ coatings are compared in figure 9. The spectra of the $\mathrm{B}_{\mathrm{x}} \mathrm{C}_{\mathrm{y}} \mathrm{N}_{\mathrm{z}}$ coatings display broad and relatively intense $\mathrm{D}$ and $\mathrm{G}$ bands, very similar to the Raman features of low temperature pyrocarbon $[59,63,66]$. In contrast, only one Raman band is expected around $1367 \mathrm{~cm}^{-1}$ in this region of the spectrum in the case of pure h-BN. This phonon corresponds to inplane vibration of $\mathrm{B}-\mathrm{N}$ bonds ( $\mathrm{E}_{2 \mathrm{~g} 2}$ symmetry) and is usually very weak compared to the equivalent $\mathrm{G}$ band of graphite [68-69]. Raman features of pyrocarbonThe RMS analyses confirm the PLM and TEM results (figure 9, table 4). The $\mathrm{R}_{\mathrm{A}}$ values decrease successively from RL-PyC to S1/S2 and eventually S3-S4, revealing a gradual decrease of anisotropy. On the other hand, the $\mathrm{w}_{\mathrm{D}}$ variations indicate that the highly textured coatings S1 and S2 contain slightly more in-plane defects than S3 and S4. This result emphasizes the need to differentiate between short range structure and anisotropy, and suggests a comparable microtexture for S1, S2 and regenerated pyrocarbon (ReL) [59, 63]. High anisotropy and high density of inplane defects are indeed often associated with lattice fringes that are highly crimped at the nanometer scale, while preferentially aligned at the submicrometer scale (figure 8 ).

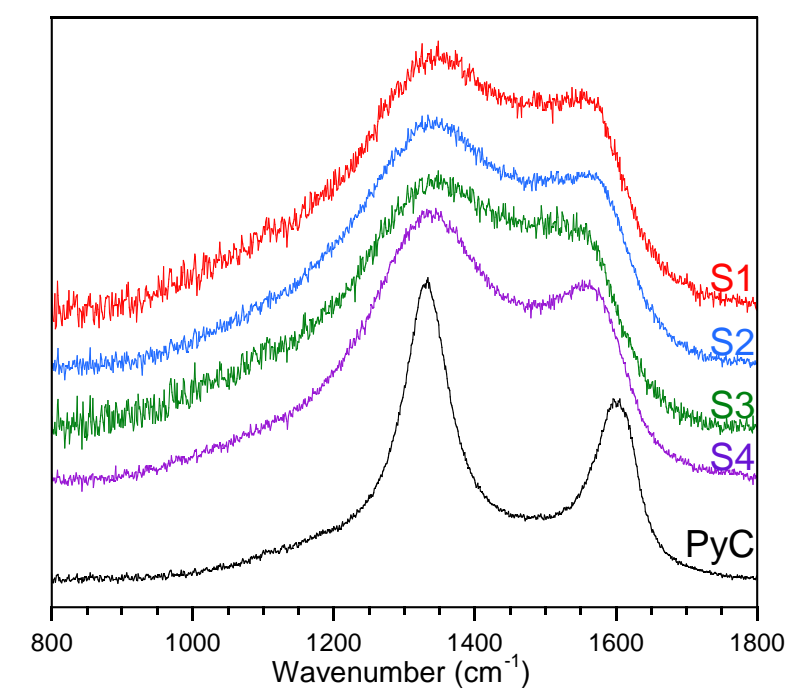

Figure 9: Raman spectra of RL-PyC and $\mathrm{S} 1$ to $\mathrm{S} 4 \mathrm{~B}_{\mathrm{x}} \mathrm{C}_{\mathrm{y}} \mathrm{N}_{\mathrm{z}}$ coatings.

The structure of the $\mathrm{B}_{\mathrm{x}} \mathrm{C}_{\mathrm{y}} \mathrm{N}_{\mathrm{z}}$ coatings was studied in more details by X-ray diffraction. The lattice parameters of h-BN, pyrolytic carbon and hexagonal boron carbonitride can be so close, that XRD on its own is 
inappropriate to differentiate between these different phases $[17,70]$. Accordingly, this technique was only used to assess the crystalline state of the coatings $\left(\mathrm{d}_{002}, \mathrm{Lc}\right)$ regardless of the nature of the phases.

\begin{tabular}{|c|c|c|c|c|c|}
\hline & RL-PyC & $\mathrm{S} 1$ & $\mathrm{~S} 2$ & $\mathrm{~S} 3$ & $\mathrm{~S} 4$ \\
\hline $\mathrm{R}_{\mathrm{A}}$ & $6.5(0.7)$ & $5.4(0.5)$ & $5.5(0.5)$ & $4.2(0.2)$ & $4.2(0.2)$ \\
\hline $\mathrm{W}_{\mathrm{D}}\left(\mathrm{cm}^{-1}\right)$ & $86(3)$ & $193(3)$ & $174(9)$ & $157(13)$ & $167(7)$ \\
\hline
\end{tabular}

Table 4: Intensity ratio $\mathrm{R}_{\mathrm{A}}$ and $\mathrm{D}$ band width $\mathrm{w}_{\mathrm{D}}$, as measured by polarized Raman microspectroscopy: comparison of a RL-PyC and S1-S4 $\mathrm{B}_{\mathrm{x}} \mathrm{C}_{\mathrm{y}} \mathrm{N}_{\mathrm{z}}$ coatings (averages values and standard deviations, in brackets, are deduced from ten different measurements).

As expected from the HRTEM analyses and confirmed in figure 10, the S1-S4 coatings exhibit a turbostratic structure with a predominating two-dimensional order. The absence of (hkl) peak for $\mathrm{h} \neq 0$ or $\mathrm{k} \neq 0$ is indeed characteristic of the lack of three-dimensional order. This structure is very similar to that of pyrocarbons deposited at low temperature. The lower $\mathrm{d}_{002}$ and larger Lc values of the $\mathrm{B}_{\mathrm{x}} \mathrm{C}_{\mathrm{y}} \mathrm{N}_{\mathrm{z}}$ coatings, compared to the PyC reference deposited in similar conditions, show that they have a better structural organization (table 5). Substitutional boron is indeed known to promote graphitization and reduce $\mathrm{d}_{002}$ in boronated carbon materials [71]. In good agreement with the TEM analyses, the XRD patterns (figure 10) show that S1 is the $\mathrm{B}_{\mathrm{x}} \mathrm{C}_{\mathrm{y}} \mathrm{N}_{\mathrm{z}}$ coating having the highest crystallinity. The coherent domains are the largest $(\mathrm{Lc} \approx 10 \mathrm{~nm})$ and the $\mathrm{d}_{002}$ distances the shortest (3.395 $\AA$ compared to $3.354 \AA$ for graphite) of all $\mathrm{B}_{\mathrm{x}} \mathrm{C}_{\mathrm{y}} \mathrm{N}_{\mathrm{z}}$ coatings. The broadening of 002 peak observed from S1 to S4 is indicative of a decrease of Lc (table 5).

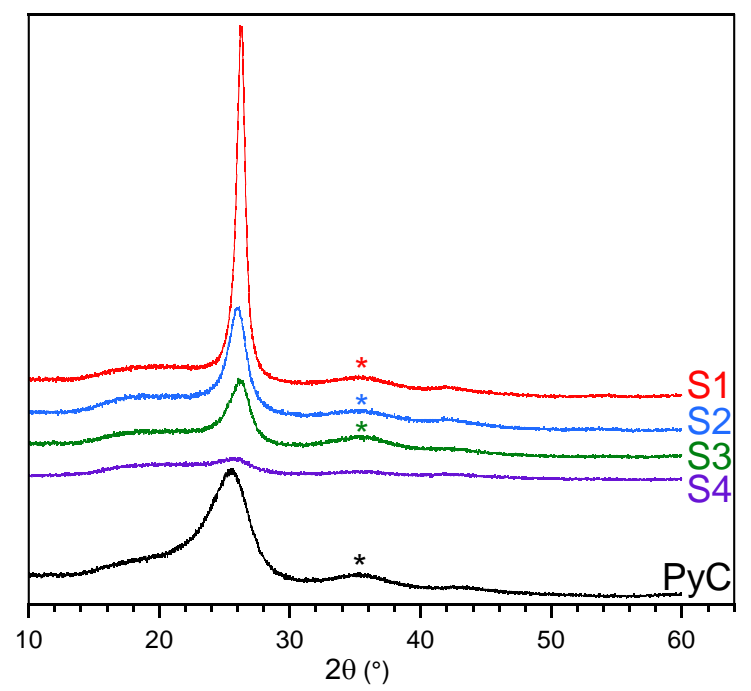

Figure 10: $\mathrm{X}$ ray diffraction patterns of pyrolytic carbon and $\mathrm{S} 1$ to $\mathrm{S} 4 \mathrm{~B}_{\mathrm{x}} \mathrm{C}_{\mathrm{y}} \mathrm{N}_{\mathrm{z}}$ coatings. $*$ The broad peak at $35.5^{\circ}$ corresponds to the $\beta$-SiC (111) nanocrystallites of the Nicalon fibers.

\begin{tabular}{|l|l|l|l|l|l|}
\hline & PyC & S1 & S2 & S3 & S4 \\
\hline
\end{tabular}




\begin{tabular}{|l|c|c|c|c|c|}
\hline $2 \theta\left(^{\circ}\right)$ & 25.36 & 26.23 & 26.10 & 25.94 & 25.7 \\
\hline $\mathrm{W}_{002}\left(^{\circ}\right)$ & 3.07 & 0.73 & 1.70 & 1.56 & 2.04 \\
\hline $\mathrm{d}_{002}(\AA)$ & 3.510 & 3.395 & 3.412 & 3.432 & 3.464 \\
\hline $\mathrm{Lc}(\mathrm{nm})$ & 2.7 & 11.3 & 4.8 & 5.3 & 4 \\
\hline
\end{tabular}

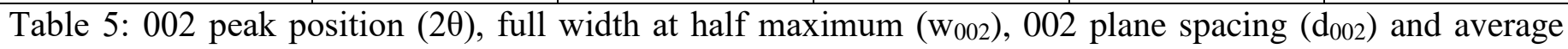
size of the coherent domains (Lc), assessed from the XRD patterns of the $\mathrm{S} 1-\mathrm{S} 4 \mathrm{~B}_{\mathrm{x}} \mathrm{C}_{\mathrm{y}} \mathrm{N}_{\mathrm{z}}$ coatings (figure 10).

The influence of the boron atomic concentration on the structural parameters $\mathrm{d}_{002}$ and $\mathrm{Lc}$ of the $\mathrm{B}_{\mathrm{x}} \mathrm{C}_{\mathrm{y}} \mathrm{N}_{\mathrm{z}}$ coatings is plotted in figure 11. The curves show a sharp maximum of $\mathrm{Lc}$ and a minimum of $\mathrm{d}_{002}$ at a boron concentration of 24 at.\% (i.e. for S1). A similar behavior was observed for boronated pyrocarbons prepared in relatively close CVD conditions [48, 72]. Two minima of both $\mathrm{w}_{002}$ and Lc were indeed detected, but in this case at 10 at\% of boron (figure 11). It is important to remind that $\mathrm{S} 1$ is the $\mathrm{B}_{\mathrm{x}} \mathrm{C}_{\mathrm{y}} \mathrm{N}_{\mathrm{z}}$ coating with the lowest nitrogen concentration $(<4$ at.\%). S2, which has the lowest boron content, is slightly better organized than S3 and S4. A low nitrogen concentration ( $<4$ at.\%) and a relatively high concentration of boron are necessarily associated with the incorporation of a large amount of B in the carbon hexagonal layers. The homogeneous distribution of isolated B-N bonds in the layers probably leads in this case to a high crystalline state and anisotropy of the S1 coating. On the other hand, a higher nitrogen concentration ( $\geq 7$ at. \%) at still relatively high $B$ concentration reduces both crystallinity and anisotropy of the S3-S4 coatings. The introduction of a larger number of B-N bonds likely leads to hexagonal layers with alternate h-BN and hboronated carbon clusters, to the detriment of the $\mathrm{B}_{\mathrm{x}} \mathrm{C}_{\mathrm{y}} \mathrm{N}_{\mathrm{z}}$ solid solution.

$\mathrm{S} 1$, with only a few isolated B-N bonds in the hexagonal boronated carbon (h-B-C) layers, display the highest anisotropy and the best crystalline state at long range in the stacking direction $\left(\mathrm{d}_{002}, \mathrm{Lc}\right)$. Yet, as for the ReL pyrocarbon [59-63], HRTEM and RMS indicate that S1 involves a high concentration of defects at short range in the longitudinal direction. On the other hand, S3 and S4 contain more B-N bonds, probably gathered in h-BN clusters embedded in h-B-C domains. This structure leads to a lower amount of in-plane defects and to tangled layers with larger radii of curvature. The resulting microtexture is characterized by a lower anisotropy and a poorer organization along the $\mathrm{c}$ axis. 


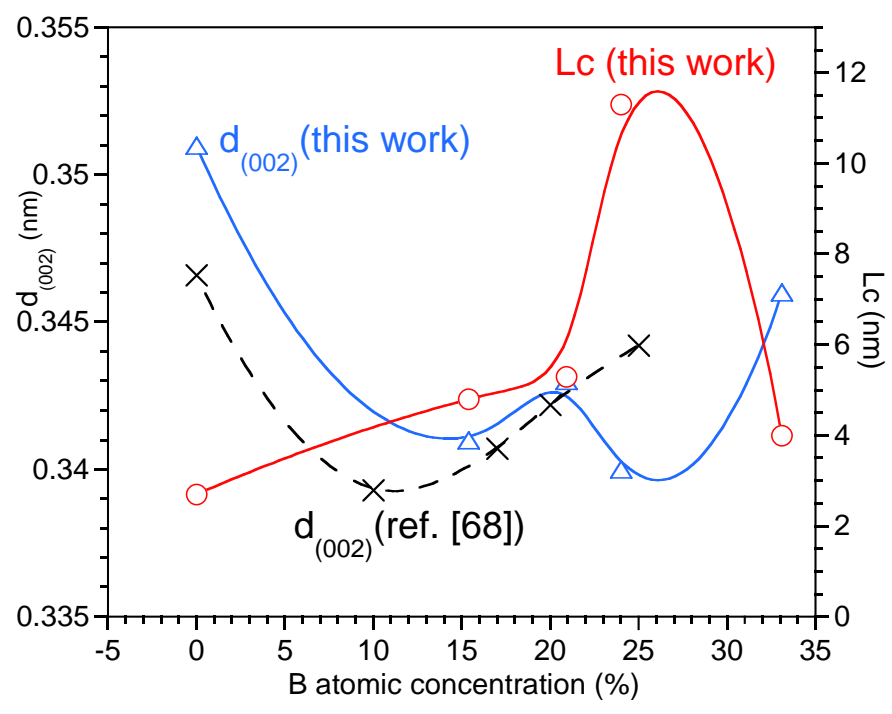

Figure 11: Influence of the boron atomic concentration of the $\mathrm{B}_{\mathrm{x}} \mathrm{C}_{\mathrm{y}} \mathrm{N}_{\mathrm{z}}$ coatings on their structural parameters Lc and d 002 .

\section{- 3.3.3 X-ray photoelectron spectroscopy XPS}

The local chemical structure of the $\mathrm{B}_{\mathrm{x}} \mathrm{C}_{\mathrm{y}} \mathrm{N}_{\mathrm{z}}$ coatings was also examined. Solid NMR [17, 48, 73] is a powerful technique but heavy and complex to conduct and interpret, especially for ${ }^{11} \mathrm{~B}$ nuclei, due to quadrupolar interactions and moreover in the case of coatings. XANES can also be used [29] but an X-ray synchrotron source is needed and the analysis is only qualitative. X-ray photoelectron spectroscopy (XPS) is clearly more accessible and accordingly, it has been used to address the possible existence of B-C-N solid solutions [24, 34, 42, 74-76]. The semi-quantitative chemical composition of the extreme surface can be measured and the nature of the nearest-neighbor atoms of a given element assessed by comparing the binding energies to values for reference materials. The main limitation of XPS is related to surface contamination making the spectra analysis sometimes difficult to interpret. In situ $\mathrm{Ar}^{+}$sputtering can eliminate $\mathrm{O}$ and $\mathrm{C}$ contaminants but it may also alter the spectral features and therefore the chemical bonding analyses. For this reason, the analyses were carried out without sputtering and considered only qualitatively for comparison of the various $\mathrm{B}_{\mathrm{x}} \mathrm{C}_{\mathrm{y}} \mathrm{N}_{\mathrm{z}}$ coatings. The specimens were kept away from air and moisture to limit contamination.

The surface atomic concentrations of the S1-S4 coatings are presented in table 6. The compositions of S1, S2 and S3 are all close. S4 having the lowest concentration of carbon also displays the highest oxygen amount. This sign of a high surface reactivity might be due to the disordered structure and high boron concentration of this coating.

\begin{tabular}{|c|c|c|c|c|}
\hline & $\mathrm{x}_{\mathrm{B}}($ at.\%) & $\mathrm{x}_{\mathrm{C}}($ at.\%) & $\mathrm{x}_{\mathrm{N}}($ at.\%) & $\mathrm{x}_{\mathrm{O}}$ (at.\%) \\
\hline S1 & 19.6 & 67.4 & 4.3 & 8.7 \\
\hline S2 & 18.4 & 68.3 & 4.8 & 7.8 \\
\hline S3 & 18.7 & 68.9 & 4.6 & 7.6 \\
\hline
\end{tabular}




\begin{tabular}{l|l|l|l|l|} 
S4 & 30.8 & 54.6 & 3.2 & 11.0 \\
\hline
\end{tabular}

Table 6: Surface atomic concentration $\mathrm{x}_{\mathrm{i}}$, as measured by XPS

To facilitate the assignment of the $\mathrm{B}_{1 \mathrm{~s}}, \mathrm{~N}_{1 \mathrm{~s}}$ and $\mathrm{C}_{1 \mathrm{~s}}$ XPS features, the various attributions of the binding energies reported by other authors for similar materials were compared in figure 12 [8, 24, 34, 42, 46-48, 7077]). Moreover, a boronated carbon coating was synthesized in the same reactor using a $\mathrm{C}_{3} \mathrm{H}_{8}-\mathrm{BCl}_{3}-\mathrm{H}_{2}$ mixture of respectively 48, 12 and $150 \mathrm{sccm}$. This coating, referred to as $\mathrm{B}_{\mathrm{x}} \mathrm{C}_{\mathrm{y}}$, was deposited at $950^{\circ} \mathrm{C}$ and $4 \mathrm{kPa}$. Its composition, as measured by EPMA, is $\mathrm{B}_{0.04} \mathrm{C}_{0.96}$. The $\mathrm{B}_{\mathrm{x}} \mathrm{C}_{\mathrm{y}}$ coating was analyzed by XPS in the same conditions as the $\mathrm{B}_{\mathrm{x}} \mathrm{C}_{\mathrm{y}} \mathrm{N}_{\mathrm{z}}$ coatings and the peak fitting was achieved according to the same procedure. The $\mathrm{B}_{\mathrm{x}} \mathrm{C}_{\mathrm{y}}$ material could then serve as an internal reference instead of simply referring to previous works. The h-BN type bond on the $\mathrm{B}_{1 \mathrm{~s}}$ spectrum is identified at $190.7 \mathrm{eV}$ in agreement with the literature $[8,42,75$, 77]. The lower energy 187.5 and $188.4 \mathrm{eV}$ components correspond to bonds present in the binary B-C, with more electropositive environments of the boron atoms. From the comparison between the $\mathrm{B}_{\mathrm{x}} \mathrm{C}_{\mathrm{y}} \mathrm{N}_{\mathrm{z}}$ and the $\mathrm{B}_{\mathrm{x}} \mathrm{C}_{\mathrm{y}}$ spectra, it appears that the $188.4 \mathrm{eV}$ peak could be assigned to hexagonal boron-substituted carbon (hB-C) [8, 46-48]. It should nevertheless be noted that the reported binding energies associated to this type of material are highly scattered (figure 12). The $187.5 \mathrm{eV}$ peak, on the other hand, corresponds for most authors to boron carbide $\left(\mathrm{B}_{4} \mathrm{C}\right)$ [46-47, 74]. Saugnac et al. nevertheless attributed a $187.3 \mathrm{eV}$ feature to $B-C_{3}$ environments (atomic environments are given in italics in the following) [34]. The higher energy $189.5 \mathrm{eV}$ component could be then attributed to boron atoms in a mixed hexagonal $\mathrm{C} / \mathrm{N}$ environment (h-B-C-N), in agreement with other authors [42, 74]. It is indeed intense for $\mathrm{B}_{\mathrm{x}} \mathrm{C}_{\mathrm{y}} \mathrm{N}_{\mathrm{z}}$ coatings and weak for the $\mathrm{B}_{\mathrm{x}} \mathrm{C}_{\mathrm{y}}$ reference, possibly due to surface oxidation. More electronegative boron environments than $B-N_{3}$ (in h-BN) appear at energies beyond $190.7 \mathrm{eV}$ for oxidized boron sites such as $B-C_{n} O_{3-n}, B-N_{n} O_{3-n}$ and $B-O_{3}$, successively (figure 12). $B-O_{3}$ in $\mathrm{B}_{2} \mathrm{O}_{3}$ is expected around $192.8 \mathrm{eV}$ [34, 46-47, 77]. The binding energy distribution found in literature for the various oxidized B sites is obviously broader (figure 12). For simplification, a common value of $191.8 \mathrm{eV}$ was attributed to the mixed $B-C_{n} O_{3-n}$ or $B-N_{n} O_{3-n}$ sites for the fitting of the $\mathrm{B}_{1 \mathrm{~s}}$ spectra. All the binding energy values used for the fitting of the $\mathrm{B}_{1 \mathrm{~s}}$ spectra and the corresponding atomic environments are gathered in table $7 \mathrm{a}$.

The various $B_{1 s}$ spectra (figure 13) reveal that boron sites attributed to h-B-C generally prevail in both $B_{x} C_{y}$ and $\mathrm{B}_{\mathrm{x}} \mathrm{C}_{\mathrm{y}} \mathrm{N}_{\mathrm{z}}$ coatings. As expected, relatively intense additional peaks are also visible for the $\mathrm{B}_{\mathrm{x}} \mathrm{C}_{\mathrm{y}} \mathrm{N}_{\mathrm{z}}$ coatings, attributed to $B-N_{3}$ and $B-N_{n} C_{3-n}$ sites. The intensity of the component assigned to boron clusters is on the other hand extremely weak in all materials. 

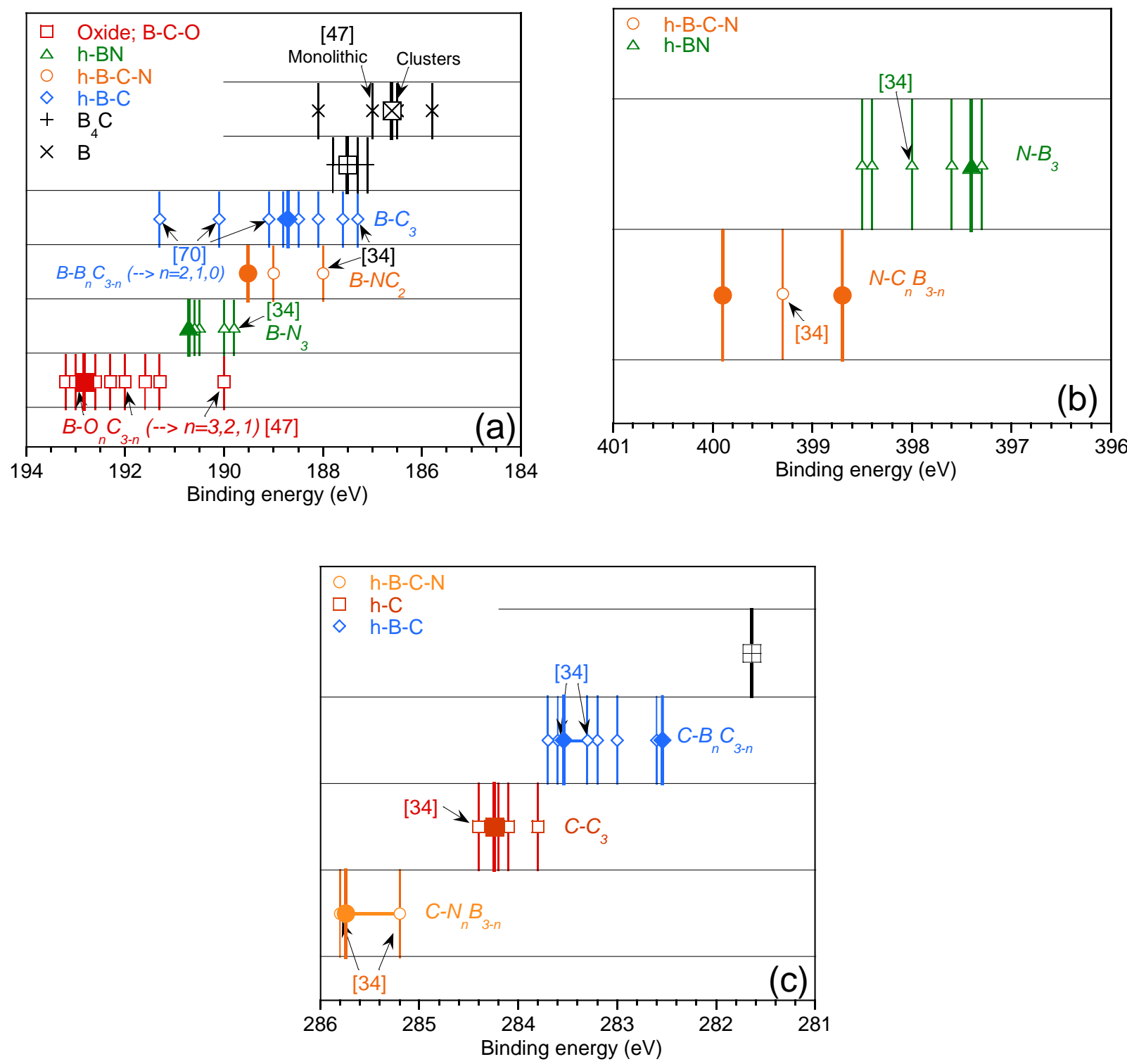

Figure 12: Distribution of binding energies, extracted from literature [8, 24, 34, 42, 46-48, 71-77] (open symbols), current values used for the fitting (solid and larger symbol) and attribution to standard compounds and atomic environments: (a) $\mathrm{B}_{1 \mathrm{~s}}$, (b) $\mathrm{N}_{1 \mathrm{~s}}$ and (c) $\mathrm{C}_{1 \mathrm{~s}}$ core levels

The $\mathrm{N}_{1 \mathrm{~s}}$ spectra of the $\mathrm{B}_{\mathrm{x}} \mathrm{C}_{\mathrm{y}} \mathrm{N}_{\mathrm{z}}$ coatings exhibit a main peak at $397.4 \mathrm{eV}$. This component was assigned to $N$ $B_{3}$ environments (as in h-BN), although such a value seems rather low compared to those usually reported around $398.0 \mathrm{eV}$ (figure 12). Several other components appear at higher energy revealing a variety of atomic environments. Even though the value appears low again, the $398.7 \mathrm{eV}$ peak used for the fitting could correspond to mixed $N-B_{2} C$ or $N-B C_{2}$ sites $[24,34,76]$. The higher energy peak at $399.9 \mathrm{eV}$ could be related to $\mathrm{N}-\mathrm{C}_{3}$ environments or more likely to some partially oxidized nitrogen sites. These peaks are particularly intense on the $\mathrm{N}_{1 \mathrm{~s}}$ spectrum of the B-rich $\mathrm{S} 4$ coating that was indeed found more oxidized at surface than the other coatings (table 6). Other features appearing beyond $400 \mathrm{eV}$ were related to more oxidized nitrogensites (table 7b). 

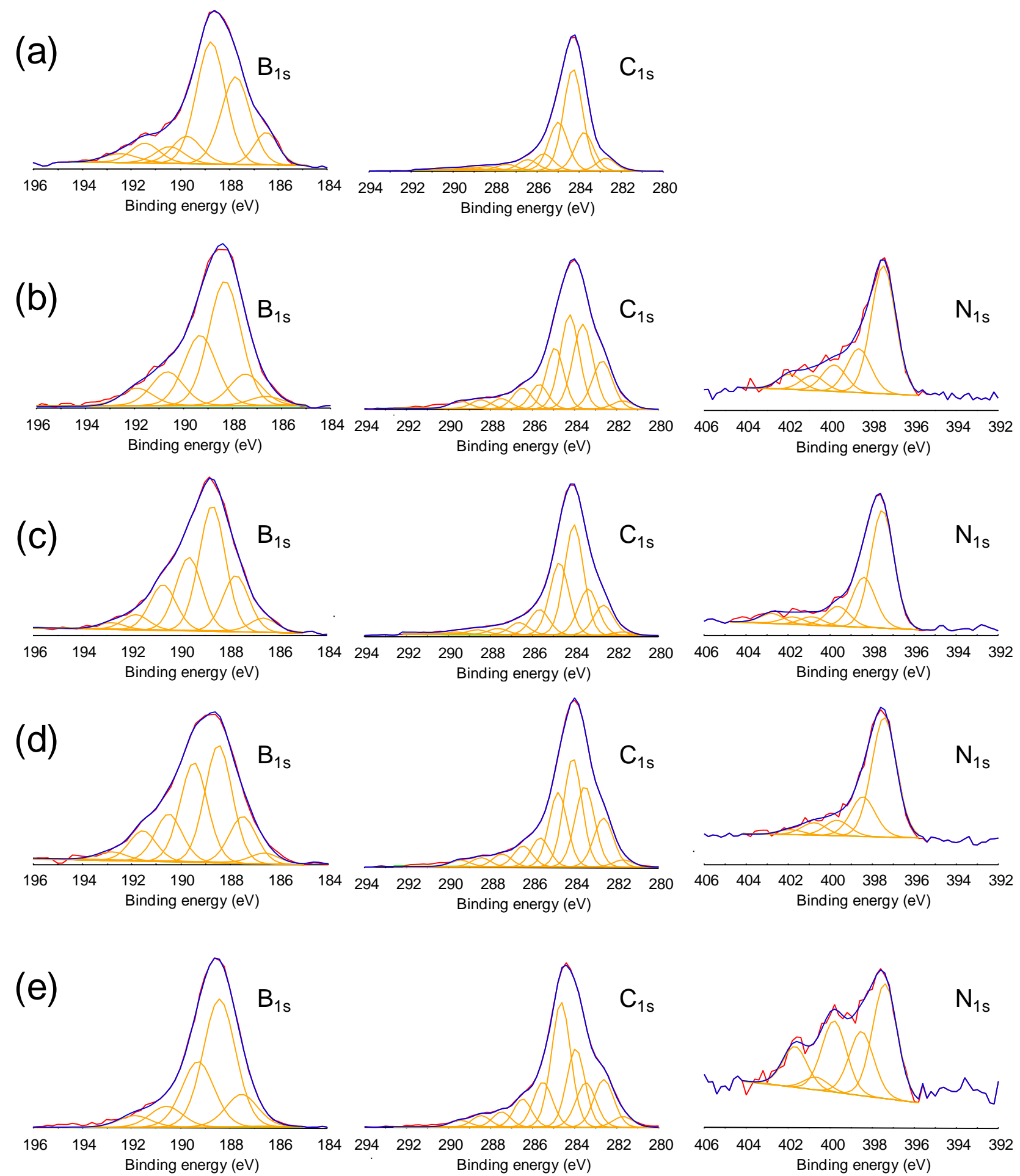

Figure 13: High resolution XPS spectra of the (a) reference $B_{x} C_{y}$ and $B_{x} C_{y} N_{z}$ coatings: (b) $S 1$, (c) S2, (d) S3 and (e) S4

The $\mathrm{C}_{1 \mathrm{~s}}$ spectra are extremely complex to analyze due to the many different bonds formed by surface contamination. The main component correspond to $\mathrm{sp}^{2}$ type $C-C_{3}$ sites at $284.3 \mathrm{eV}$. The previous studies on h-B-C and h-B-C-N materials conclude that binary $C-B_{n} C_{3-n}$ and ternary $C-N_{n} B_{3-n}$ environments are expected respectively at lower and higher energies compared to the $284.3 \mathrm{eV}$ of $\mathrm{sp}^{2}$ carbon (figure 12). In agreement with the large distribution observed in the literature $[34,48,72,74,76]$, two $C-B_{n} C_{3-n}$ components were considered for the fit the $\mathrm{C}_{1 \mathrm{~s}}$ spectra, which can be related respectively to boron-rich $(282.6 \mathrm{eV})$ and either carbon-rich $C-B_{n} C_{3-n}$ or partially oxidized $\left(C-B_{n} O_{3-n}\right)$ environments $(283.6 \mathrm{eV}$, table 7$)$. 


\begin{tabular}{|c|c|c|}
\hline $\mathrm{B}_{2} \mathrm{O}_{3}$ & $B-O_{3}$ & $192.8 \mathrm{eV}$ \\
\hline "Oxides" & $B-C_{n} O_{3-n} / B-N_{n} O_{3-n}$ & $191.8 \mathrm{eV}$ \\
\hline h-BN & $B-N_{3}$ & $190.7 \mathrm{eV}$ \\
\hline h-B-C-N & $B-N_{n} C_{3-n}$ & $189.5 \mathrm{eV}$ \\
\hline h-B-C & $B-B_{n} C_{3-n}$ & $188.4 \mathrm{eV}$ \\
\hline B 4 C / h-B-C & $-/ B-C_{3}$ & $187.5 \mathrm{eV}$ \\
\hline B (clusters) & - & $186.6 \mathrm{eV}$ \\
\hline
\end{tabular}

(a)

\begin{tabular}{|c|c|c|}
\hline “Oxides" & $?$ & $401.9 \mathrm{eV}$ \\
\hline “Oxides" & $N-C_{n} O_{3-n}$ & $400.8 \mathrm{eV}$ \\
\hline h-B-C-N / oxidized h-BN & $N-C_{3} / N-O_{n} B_{3-n}$ & $399.9 \mathrm{eV}$ \\
\hline h-B-C-N & $N-C_{n} B_{3-n}$ & $398.7 \mathrm{eV}$ \\
\hline h-BN & $N-B_{3}$ & $397.4 \mathrm{eV}$ \\
\hline
\end{tabular}

(b)

\begin{tabular}{|c|c|c|}
\hline "Oxides" & $?$ & 289.4 to $286.6 \mathrm{eV}$ \\
\hline h-B-C-N & $C-N_{n} B_{3-n}$ & $285.8 \mathrm{eV}$ \\
\hline h-B-C-N / sp ${ }^{3} \mathrm{C}$ & $C-N_{n} B_{3-n} / ?$ & $285.0 \mathrm{eV}$ \\
\hline h-C $\left(\mathrm{sp}^{2}\right.$, graphite $)$ & $C-C_{3}$ & $284.3 \mathrm{eV}$ \\
\hline "Oxidized carbides" & $C-B_{n} C_{3-n} / C-B_{n} O_{3-n}$ & $283.6 \mathrm{eV}$ \\
\hline h-B-C & $C-B_{n} C_{3-n}$ & $282.6 \mathrm{eV}$ \\
\hline $\mathrm{B}_{4} \mathrm{C}$ & - & $281.7 \mathrm{eV}$ \\
\hline
\end{tabular}

(c)

Table 7: Chemical compounds, atomic environments and related binding energies used for the fitting of the $\mathrm{B}_{1 \mathrm{~s}}(\mathrm{a}), \mathrm{N}_{1 \mathrm{~s}}(\mathrm{~b})$ and $\mathrm{C}_{1 \mathrm{~s}}(\mathrm{c})$ XPS spectra (figure 13)

Similarly, two components were applied at the high energy side of the spectrum (285.0 and $285.8 \mathrm{eV}$ ), associated to ternary $C-N_{n} B_{3-n}$ environments [34], but also possibly to $\mathrm{sp}^{3}$ carbon or $\mathrm{C}-\mathrm{C}=\mathrm{O}$ functions from surface contamination. Further weak components due to more oxidized forms were finally added to fit the $\mathrm{C}_{1 \mathrm{~s}}$ spectra in the range $289.4-286.6 \mathrm{eV}$.

The XPS data suggest a structure for $\mathrm{B}_{\mathrm{x}} \mathrm{C}_{\mathrm{y}} \mathrm{N}_{\mathrm{z}}$ involving hexagonal boronated carbon domains mainly consisting of $\underline{\mathrm{C}}-\mathrm{C}_{3}$ sites for the carbon atoms and mixed environments for the boron atoms: $\underline{B}-\mathrm{C}_{3}, \underline{B}-\mathrm{BC}_{2}$ and B-B ${ }_{2}$ C. B-B, N-N and C-N bonds are not favorable for the stability of the hexagonal structure [78]. 
Accordingly, the number of $\underline{B}-\mathrm{B}_{2} \mathrm{C}$ environments is probably low, especially for low boron concentrations. $\underline{\mathrm{N}}-\mathrm{B}_{3}$ sites are by far the major nitrogen sites, as in h-BN. Clusters of h-BN could be present in some proportions, in particular for high $\mathrm{B}$ and $\mathrm{N}$ concentrations. The large bandwidth of the various components on the $\mathrm{N}_{1 \mathrm{~s}}$ and $\mathrm{B}_{1 \mathrm{~s}}$ spectra suggests, however, that other combinations of atomic bonding could be present, though in the minority.

\subsection{Oxidation resistance of the $\mathrm{B}_{\mathrm{x}} \mathrm{C}_{\mathrm{y}} \mathrm{N}_{\mathrm{z}}$ coatings}

The overall reaction expected for the oxidation of $\mathrm{B}_{\mathrm{x}} \mathrm{C}_{\mathrm{y}} \mathrm{N}_{\mathrm{z}}$ coatings can be represented by the balance equation (1):

$$
B_{x} C_{y} N_{z}+\left(y+\frac{3}{4} x\right) O_{2} \rightarrow y C O_{2}+\frac{z}{2} N_{2}+\frac{x}{2} B_{2} O_{3}
$$

This equation is consistent with the study on the oxidation behavior of similar materials from Derré et al. [44]. These authors indeed observed that boron oxide $\mathrm{B}_{2} \mathrm{O}_{3}$ is the only condensed species formed by oxidation in dry air between 800 and $1200^{\circ} \mathrm{C}$. The weight change corresponding to the oxidation of one mole of $\mathrm{B}_{\mathrm{x}} \mathrm{C}_{\mathrm{y}} \mathrm{N}_{\mathrm{z}}$ is accordingly:

$$
\Delta m\left(B_{x} C_{y} N_{z}\right)=O_{m a s s} * \frac{3}{2} x-C_{m a s s} * y-N_{m a s s *} Z
$$

This simple equation shows that, depending on the $\mathrm{B}_{\mathrm{x}} \mathrm{C}_{\mathrm{y}} \mathrm{N}_{\mathrm{z}}$ composition, the oxidation can result in a weight loss or gain, or even no mass change at all. The boundary between weight loss and gain is a line on the ternary B-C-N diagram linking the two hypothetical compositions $\mathrm{B}_{0.31} \mathrm{C}_{0.69}$ and $\mathrm{B}_{0.37} \mathrm{~N}_{0.63}$. It is worthy of note that S1, S2 and S3 are expected to lose weight upon oxidation whereas the high boron and low carbon content S4 coating is on the "weight gain" side of the diagram, close to the "constant weight" line.

\section{- 3.4.1 High temperature $\left(550-700^{\circ} \mathrm{C}\right)$ oxidation in dry air}

The TGA curves recorded for the various $\mathrm{B}_{\mathrm{x}} \mathrm{C}_{\mathrm{y}} \mathrm{N}_{\mathrm{z}}$ coatings and the reference pyrocarbon material are compared in figure 14. Two identical TGA runs were carried out on two $\mathrm{B}_{\mathrm{x}} \mathrm{C}_{\mathrm{y}} \mathrm{N}_{\mathrm{z}}$ samples of the same batch to appraise the test-retest reliability (figure 14a). All S1-S4 coatings lose weight when oxidized in dry air. The weight loss rate increases from S4 to S1, S3 and S2, i.e. when the boron content decreases. In comparison, the oxidation rate of the pyrocarbon coating in the same conditions is much higher (figure 14b). This behavior is in good agreement with equation 2, except for S4, for which a very slight weight gain was expected. This discrepancy could be related to some volatilization of the oxide due to traces of impurities in the coating $(\mathrm{Cl}, \mathrm{H})$ or in the atmosphere, or even to uncertainty in the $\mathrm{B}_{\mathrm{x}} \mathrm{C}_{\mathrm{y}} \mathrm{N}_{\mathrm{z}}$ atomic composition. 

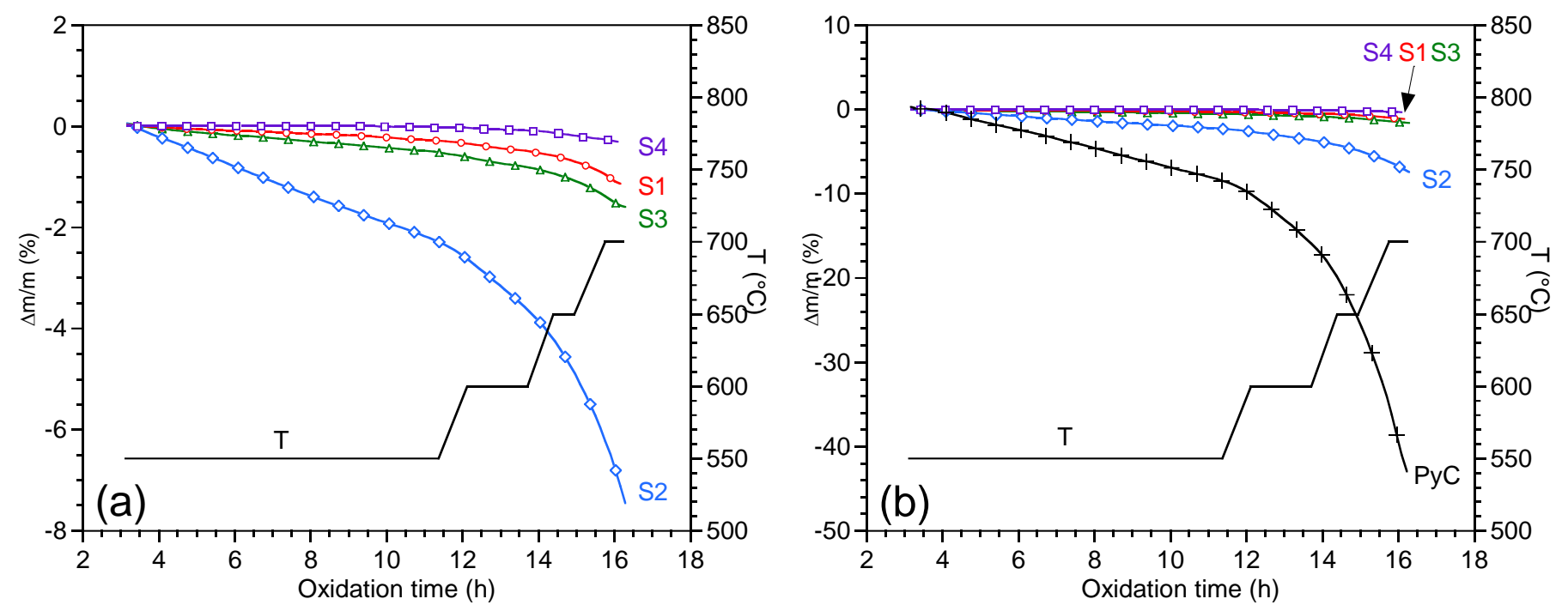

Figure 13: Weight change during the oxidation of $\mathrm{B}_{\mathrm{x}} \mathrm{C}_{\mathrm{y}} \mathrm{N}_{\mathrm{z}}$ coatings in dry air between 550 and $700^{\circ} \mathrm{C}$. (a) Comparison between $\mathrm{S} 1$ to $\mathrm{S} 4$. (b) Comparison between pyrocarbon and $\mathrm{B}_{\mathrm{x}} \mathrm{C}_{\mathrm{y}} \mathrm{N}_{\mathrm{z}}$ coatings.

The oxidation behavior was further investigated by SEM observations of cross sections of the coatings after the TGA experiments. The SEM micrographs displayed in figure 15 reveal the progress of oxidation through the recession of the $\mathrm{B}_{\mathrm{x}} \mathrm{C}_{\mathrm{y}} \mathrm{N}_{\mathrm{z}}$ coating and the growth of the oxide layer.
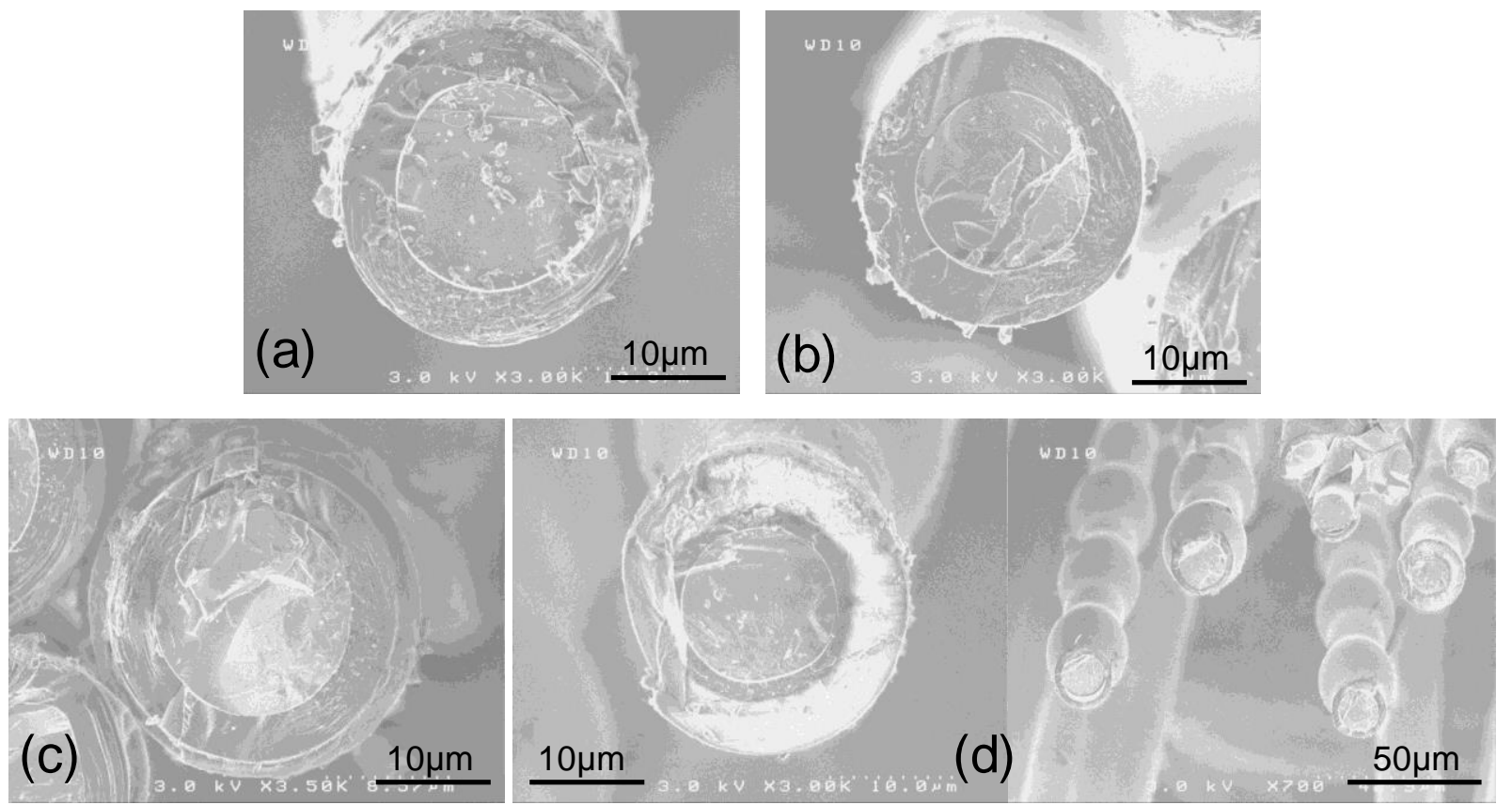

Figure 15: Cross section of S1 and S4 coatings on SiC fibers before: (a) S1, (b) S4, and after oxidation up to $700^{\circ} \mathrm{C}$ : (c) S1 and (d) S4.

For specimen S4, the thick outer layer appearing in white after oxidation, due to charging effects, was found by EDS to consist of pure $\mathrm{B}_{2} \mathrm{O}_{3}$. Only a thin unoxidized $\mathrm{B}_{\mathrm{x}} \mathrm{C}_{\mathrm{y}} \mathrm{N}_{\mathrm{z}}$ layer is visible at the fiber/oxide interface indicating that the specimen was nearly fully oxidized. The recession in thickness is of approximately $3 \mu \mathrm{m}$. The irregular shape of the oxide layer, forming droplets, is characteristic of the formation of large amounts 
of fluid oxide. The outer surface and the section of S1 after oxidation are in contrast more regular. The thickness of $\mathrm{S} 1$ consumed is only $0.8 \mu \mathrm{m}$ and the $\mathrm{B}_{2} \mathrm{O}_{3}$ layer formed is limited to $1.8 \mu \mathrm{m}$ (figure 15), confirming that the $\mathrm{B}_{\mathrm{x}} \mathrm{C}_{\mathrm{y}} \mathrm{N}_{\mathrm{z}}$ recession and $\mathrm{B}_{2} \mathrm{O}_{3}$ growth rates are both reduced compared to $\mathrm{S} 4$. The better oxidation resistance of $\mathrm{S} 1$ is probably due to its better cristalline state, as evidenced by XRD and TEM analyses (figure 8, 10).

The oxidation kinetics obey a linear law in the range 550 to $700^{\circ} \mathrm{C}$ for all the coatings and the oxidation rates increase with temperature. In spite of the growth of a $\mathrm{B}_{2} \mathrm{O}_{3}$ layer at the surface of the $\mathrm{B}_{\mathrm{x}} \mathrm{C}_{\mathrm{y}} \mathrm{N}_{\mathrm{z}}$ coatings, no parabolic law characteristic of a passive oxidation regime could be observed. This behavior suggests that the process is more likely limited by the $\mathrm{B}_{\mathrm{x}} \mathrm{C}_{\mathrm{y}} \mathrm{N}_{\mathrm{z}} / \mathrm{B}_{2} \mathrm{O}_{3}$ interfacial reaction than $\mathrm{O}_{2}$ diffusion through the growing oxide layer. The apparent activation energies of the linear rates fall in the range $90-130 \mathrm{~kJ} / \mathrm{mole}$ for all $\mathrm{B}_{\mathrm{x}} \mathrm{C}_{\mathrm{y}} \mathrm{N}_{\mathrm{z}}$ coatings, close to the value measured for pyrocarbon in similar conditions $(120 \mathrm{~kJ} / \mathrm{mole})$. This behavior suggests a common limiting chemical reaction step in both pyrocarbon and $\mathrm{B}_{\mathrm{x}} \mathrm{C}_{\mathrm{y}} \mathrm{N}_{\mathrm{z}}$ oxidation mechanisms. The lower concentration of carbon active sites and the presence of boron atoms inhibiting $\mathrm{O}_{2}$ chemisorption could explain the lower recession rate of $\mathrm{B}_{\mathrm{x}} \mathrm{C}_{\mathrm{y}} \mathrm{N}_{\mathrm{z}}$ compared to pyrocarbon $[71,79]$.

\section{- 3.4.2 Low temperature $\left(450^{\circ} \mathrm{C}\right)$ oxidation in dry air}

The very beginning of the oxidation process can be better assessed at low temperature. After oxidation during $15 \mathrm{~h}$ in dry air at $450^{\circ} \mathrm{C}$, the surface of the oxidized $\mathrm{B}_{\mathrm{x}} \mathrm{C}_{\mathrm{y}} \mathrm{N}_{\mathrm{z}}$ coatings reveals the formation of boron oxide islands, which tend to grow proportionally in size with the initial boron content in the films (figure 16).
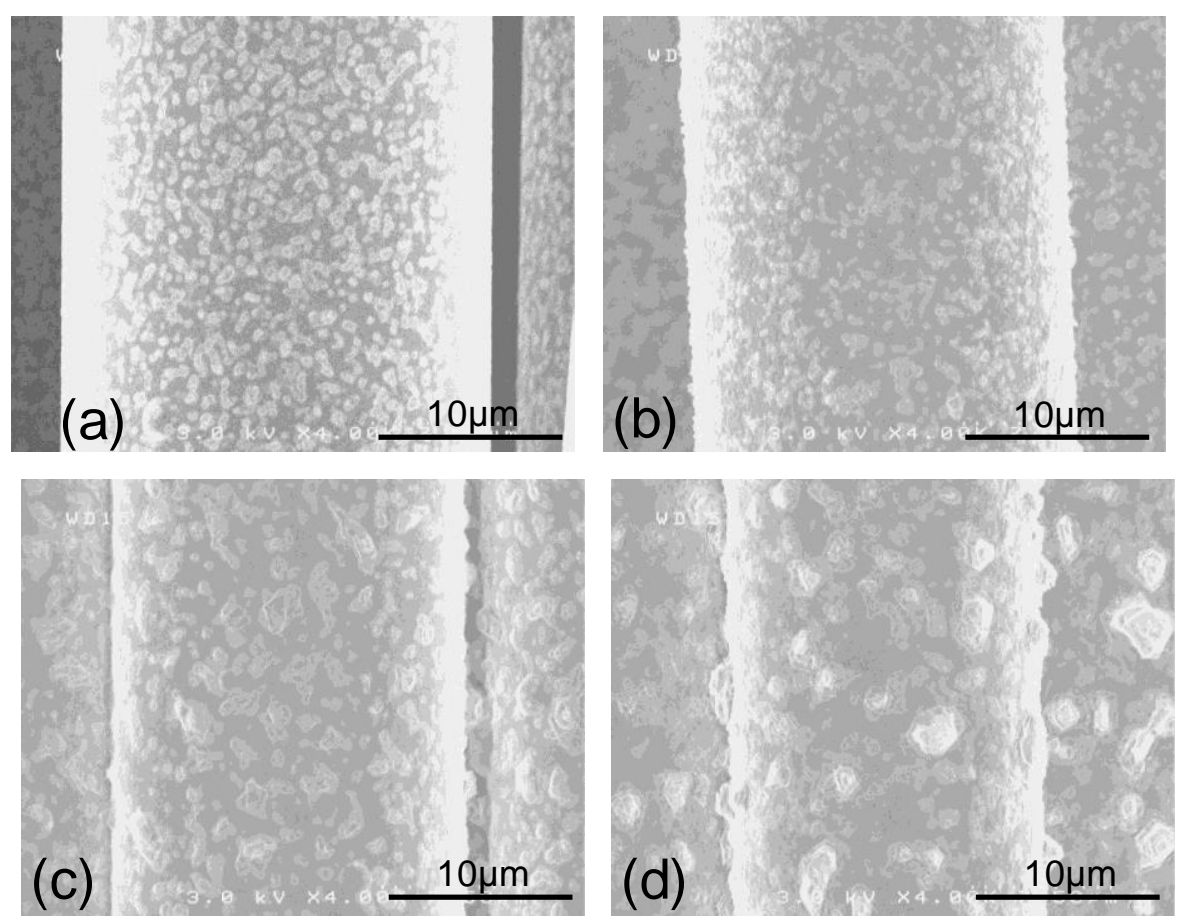

Figure 16: Surface of (a) S1, (b) S2, (c) S3 and (d) S4 coatings after oxidation during 15h in dry air at $450^{\circ} \mathrm{C}$. The as-deposited coatings are approximately $1 \mu \mathrm{m}$ thick. 
The four $\mathrm{B}_{\mathrm{x}} \mathrm{C}_{\mathrm{y}} \mathrm{N}_{\mathrm{z}}$ coatings as well as the reference pyrocarbon film were oxidized under ambient air at both $450^{\circ} \mathrm{C}$ and $550^{\circ} \mathrm{C}$. The water vapor partial pressure in the vicinity of the furnace remained in the range 0.7 to $1 \mathrm{kPa}$ during the complete annealing treatments. To determine the recession rate, the thickness of the coatings (around $5 \mu \mathrm{m}$ for all specimens) was accurately measured by SEM before starting the tests and after different exposure times.

The oxidation behavior is noticeably different for the various materials even at relatively low water vapor pressures. The recession rate is indeed higher for the $\mathrm{B}_{\mathrm{x}} \mathrm{C}_{\mathrm{y}} \mathrm{N}_{\mathrm{z}}$ coatings than for the pyrocarbon reference (figure 17). At $450^{\circ} \mathrm{C}$, the pyrocarbon is only very slightly oxidized after $250 \mathrm{~h}$, whereas the $\mathrm{B}_{\mathrm{x}} \mathrm{C}_{\mathrm{y}} \mathrm{N}_{\mathrm{z}}$ coatings are significantly consumed (figure $17 \mathrm{a}$ ). At $550^{\circ} \mathrm{C}$, the oxidation kinetics increase but the difference in the behavior between $\mathrm{B}_{\mathrm{x}} \mathrm{C}_{\mathrm{y}} \mathrm{N}_{\mathrm{z}}$ and pyrocarbon is less pronounced (figure 17b). It is well known that the partial pressure of water vapor has a very limited effect on the oxidation of carbon materials [80-81]. On the contrary, as already reported for h-BN $[55,82]$, the $\mathrm{H}_{2} \mathrm{O}$ pressure has a strong influence on the oxidation behavior of $\mathrm{B}_{\mathrm{x}} \mathrm{C}_{\mathrm{y}} \mathrm{N}_{\mathrm{z}}$ materials. In presence of moisture, condensed boron oxide is no longer stable but reacts with $\mathrm{H}_{2} \mathrm{O}$ to form gaseous species such as $\mathrm{H}_{3} \mathrm{~B}_{3} \mathrm{O}_{6}, \mathrm{H}_{3} \mathrm{BO}_{3}$ and mainly $\mathrm{HBO}_{2}$ above $600^{\circ} \mathrm{C}$. The main consequence on the oxidation process, compared to dry air, is the additional contribution of boron oxide species to the weight loss. Cofer et al. [54] have shown that the oxidation of boron nitride in presence of water vapor is directly related to the crystalline state of h-BN. The same apparently holds true for $B_{x} C_{y} N_{z}$ materials since the S1 coating, with high crystallinity, exhibits a better corrosion resistance than the disordered S4.
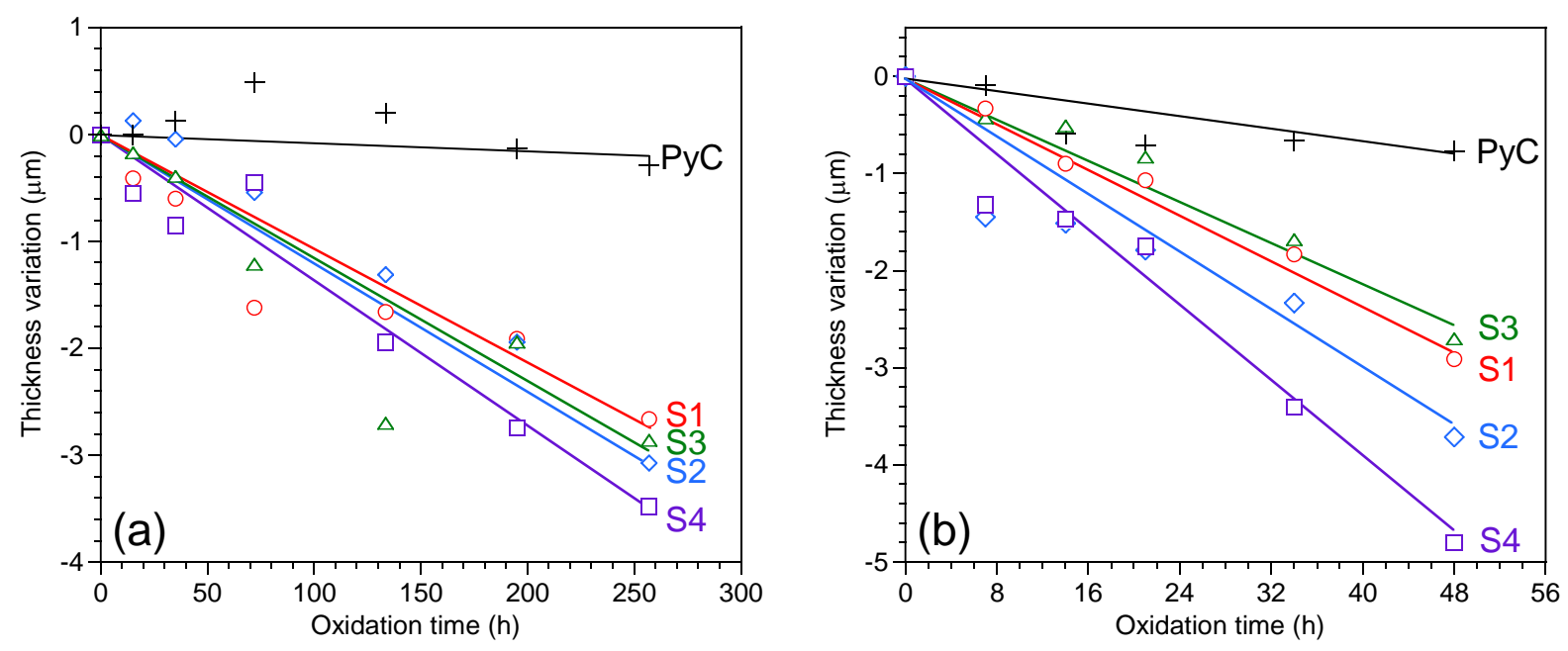

Figure 17: thickness versus time during the oxidation in ambient air of pyrocarbon and $\mathrm{B}_{\mathrm{x}} \mathrm{C}_{\mathrm{y}} \mathrm{N}_{\mathrm{z}}$ coatings at (a) $450^{\circ} \mathrm{C}$ and (b) $550^{\circ} \mathrm{C}$.

- 3.4.4 Influence of the deposition temperature and post-deposition heat treatments Cholet et al.1994 [77] have studied the influence of the deposition conditions on the structure and the stability in ambient air of hexagonal boron nitride CVD coating. Besides the effect of pressure, initial gas composition and temperature, they noticed that room temperature oxidation in air could be significantly reduced by heat treatments above the deposition temperature. Surprisingly, similar studies at higher 
oxidation temperatures are not reported either for $\mathrm{h}-\mathrm{BN}$ or $\mathrm{B}_{\mathrm{x}} \mathrm{C}_{\mathrm{y}} \mathrm{N}_{\mathrm{z}}$ solid solutions. Since the oxidation of $\mathrm{B}_{\mathrm{x}} \mathrm{C}_{\mathrm{y}} \mathrm{N}_{\mathrm{z}}$ is also expected to vary with its structural state, the influence of both deposition and post deposition heat treatment temperatures of the coatings were examined.

Two additional coatings, referred to as S5 and S6, were deposited at the same pressure and initial gas composition as for $\mathrm{S} 1$, but at deposition temperatures of $950^{\circ} \mathrm{C}$ and $1100^{\circ} \mathrm{C}$ respectively (the initial deposition temperature being $1025^{\circ} \mathrm{C}$ ). Post deposition heat treatments were carried out at $1250^{\circ} \mathrm{C}$ and $1400^{\circ} \mathrm{C}$ at atmospheric pressure under pure flowing nitrogen. The atomic concentration of the resulting coatings is shown in Table 8 . The duration of the heat treatment was short (with a heating rate of $5^{\circ} \mathrm{C} / \mathrm{s}$ and a 2 min dwell) to prevent any decomposition of the coating and limit the degradation of the SiC fibers. The first generation Nicalon fibers are indeed susceptible to thermal decomposition leading to a drop of their mechanical properties beyond $1100^{\circ} \mathrm{C}$ [83]. This effect was carefully examined by submitting uncoated fibers to the same heat treatments and verifying that the failure properties were not altered. The results presented in Table 9 do not reveal any change of the Young's modulus (E) after heat treatment at $1250^{\circ} \mathrm{C}$. An increase of $\mathrm{E}$ is even observed after heat-treatment at $1400^{\circ} \mathrm{C}$, possibly due to the growth of $\beta$-SiC nanocrystals [83]. In contrast, both tensile failure strength $\left(\sigma^{f}\right)$ and strain $\left(\varepsilon^{f}\right)$ lost $33 \%$ of their initial values after heat treatment at $1250^{\circ} \mathrm{C}$. The failure properties decreased even further when the fibers were heat treated at $1400^{\circ} \mathrm{C}$, probably owing to the decomposition of the silicon oxycarbide phase [83].

\begin{tabular}{|c|c|c|c|c|c|c|c|}
\hline Sample & $\begin{array}{c}\text { Deposition } \\
\text { temperature } \\
\left({ }^{\circ} \mathrm{C}\right)\end{array}$ & $\begin{array}{c}\text { Heat treatment } \\
\text { temperature } \\
\left({ }^{\circ} \mathrm{C}\right)\end{array}$ & $\begin{array}{c}\text { B } \\
\text { at. } \%\end{array}$ & $\begin{array}{c}\mathrm{C} \\
\text { at.\% }\end{array}$ & $\begin{array}{c}\mathrm{N} \\
\text { at.\% }\end{array}$ & $\begin{array}{c}\mathrm{O} \\
\text { at.\% }\end{array}$ & $\begin{array}{c}\mathrm{Si} \\
\text { at.\% }\end{array}$ \\
\hline Sample 5 & 950 & none & $\begin{array}{c}18.3 \\
8.1\end{array}$ & $\begin{array}{l}67.4 \\
70.9\end{array}$ & $\begin{array}{c}13.4 \\
4.5\end{array}$ & $\begin{array}{c}0.9 \\
16.5\end{array}$ & $\begin{array}{l}- \\
0\end{array}$ \\
\hline $\mathrm{S} 5-1250^{\circ} \mathrm{C}$ & 950 & 1250 & $\begin{array}{l}18.3 \\
12.2\end{array}$ & $\begin{array}{l}67.3 \\
74.9\end{array}$ & $\begin{array}{c}13.7 \\
6\end{array}$ & $\begin{array}{l}0.7 \\
6.9\end{array}$ & $\begin{array}{l}- \\
0\end{array}$ \\
\hline $\mathrm{S} 5-1400^{\circ} \mathrm{C}$ & 950 & 1400 & $\begin{array}{l}14.4 \\
14.9\end{array}$ & $\begin{array}{l}70.3 \\
59.9\end{array}$ & $\begin{array}{l}14.6 \\
11.2\end{array}$ & $\begin{array}{l}0.7 \\
5.9\end{array}$ & $\begin{array}{c}- \\
8.1\end{array}$ \\
\hline Sample 6 & 1100 & none & $\begin{array}{l}20.2 \\
40.7\end{array}$ & $\begin{array}{l}75.3 \\
46.3\end{array}$ & $\begin{array}{l}4.4 \\
2.1\end{array}$ & $\begin{array}{c}0.2 \\
10.9\end{array}$ & $\begin{array}{l}- \\
\\
0\end{array}$ \\
\hline $\mathrm{S} 6-1250^{\circ} \mathrm{C}$ & 1100 & 1250 & $\begin{array}{l}25.0 \\
32.6\end{array}$ & $\begin{array}{l}71.9 \\
52.6\end{array}$ & $\begin{array}{c}3 \\
2.9\end{array}$ & $\begin{array}{c}0.1 \\
10.6\end{array}$ & $\begin{array}{c}- \\
1.4\end{array}$ \\
\hline $\mathrm{S} 6-1400^{\circ} \mathrm{C}$ & 1100 & 1400 & $\begin{array}{l}18.3 \\
16.0\end{array}$ & $\begin{array}{l}78.3 \\
37.1\end{array}$ & $\begin{array}{c}3.3 \\
12.2\end{array}$ & $\begin{array}{l}0.1 \\
7.1\end{array}$ & $\begin{array}{c}- \\
27.6\end{array}$ \\
\hline
\end{tabular}

Table 8: Influence of deposition and post deposition heat treatment temperatures on the chemical composition of $\mathrm{B}_{\mathrm{x}} \mathrm{C}_{\mathrm{y}} \mathrm{N}_{\mathrm{z}}$ coatings (regular font: bulk, as measured by EPMA, italic: surface, as measured by $X P S)$ 
Except the temperature program, the oxidation tests of S5 and S6 were carried out using the same TGA procedure as previously applied to the S1-S4 coatings. The samples were successively held 12 hours at $500^{\circ} \mathrm{C}$ and $150 \mathrm{~min}$ at $600^{\circ} \mathrm{C}$. The comparison of the various oxidation curves (Figure 18) highlights the strong influence of both deposition and heat treatment temperatures on the oxidation resistance of the coatings. Boron oxide layers (1 to $2 \mu \mathrm{m}$ thick) were observed by SEM at the surface of S5, either as deposited or heat treated. In contrast, no oxide layer was observed at the surface of as-deposited or heattreated S6.

\begin{tabular}{|l|c|c|c|}
\hline & $\begin{array}{c}\text { Nicalon } \\
\text { NLM207 }\end{array}$ & $\begin{array}{c}\text { Nicalon NLM207 } \\
1250^{\circ} \mathrm{C} / 2 \min / \mathrm{N}_{2}\end{array}$ & $\begin{array}{c}\text { Nicalon NLM207 } \\
1400^{\circ} \mathrm{C} / 2 \mathrm{~min} / \mathrm{N}_{2}\end{array}$ \\
\hline $\mathrm{E}(\mathrm{GPa})$ & $203 \pm 13$ & $202 \pm 13$ & $269 \pm 83$ \\
\hline$\sigma^{\mathrm{F}}(\mathrm{MPa})$ & $2264 \pm 443$ & $1515 \pm 378$ & $1397 \pm 508$ \\
\hline$\varepsilon^{\mathrm{F}}(\%)$ & $1.12 \pm 0.2$ & $0.75 \pm 0.2$ & $0.58 \pm 0.3$ \\
\hline
\end{tabular}

Table 9: Influence of post deposition heat treatments on the room temperature mechanical properties of Nicalon NLM207

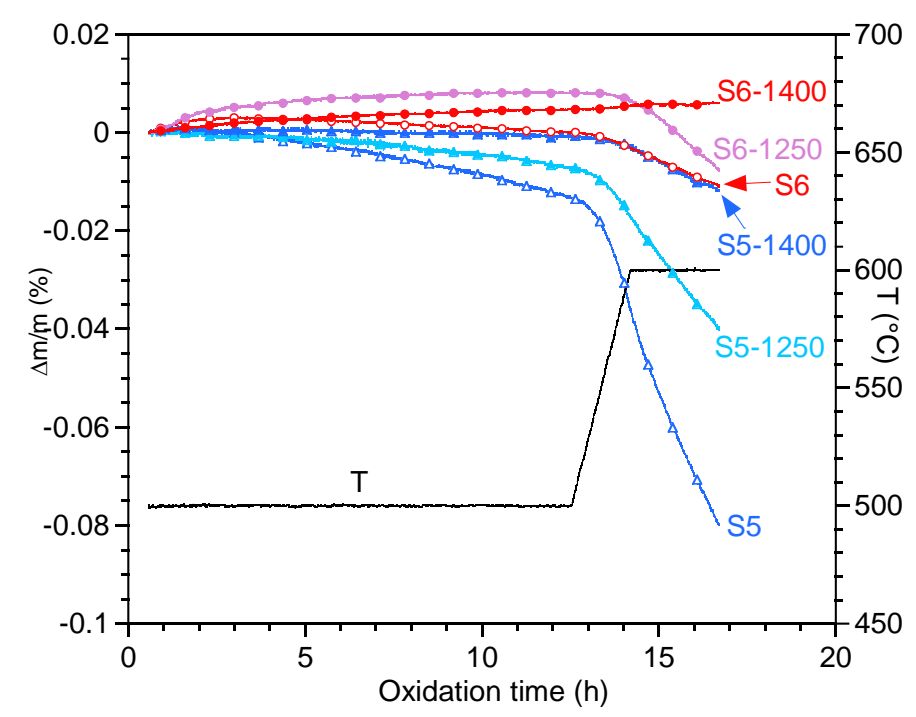

Figure 18: S5 and S6 weight variation during oxidation in ambient air following a heating sequence of $12 \mathrm{~h}$ at $500^{\circ} \mathrm{C}$ and 2.5 hour at $600^{\circ} \mathrm{C}$. Comparison between their oxidation behavior before and after heat treatments at $1250^{\circ} \mathrm{C}$ and $1400^{\circ} \mathrm{C}$.

As expected, a high deposition temperature improves the resistance against oxidation. For both specimens, the higher the heat treatment temperature, the higher the oxidation resistance. One would expect that this effect results from a better organization of the $\mathrm{B}_{\mathrm{x}} \mathrm{C}_{\mathrm{y}} \mathrm{N}_{\mathrm{z}}$ structure. This is indeed the case for the deposition temperature. The $\mathrm{Lc}$ value is $5 \mathrm{~nm}$ for coatings deposited at $950^{\circ} \mathrm{C}$ and raises up to $10 \mathrm{~nm}$ for a deposition temperature of $1100^{\circ} \mathrm{C}$. On the other hand, the analysis of the 002 diffraction peak concludes that the crystalline state of the $\mathrm{B}_{\mathrm{x}} \mathrm{C}_{\mathrm{y}} \mathrm{N}_{\mathrm{z}}$ coatings is not affected by the heat treatment temperature. To better understand the influence of the heat-treatment on the material at atomic scale, the surface composition and 
atomic environments of the as-deposited and heat-treated S5 and S6 coatings were examined by XPS (table 8, figure 19).
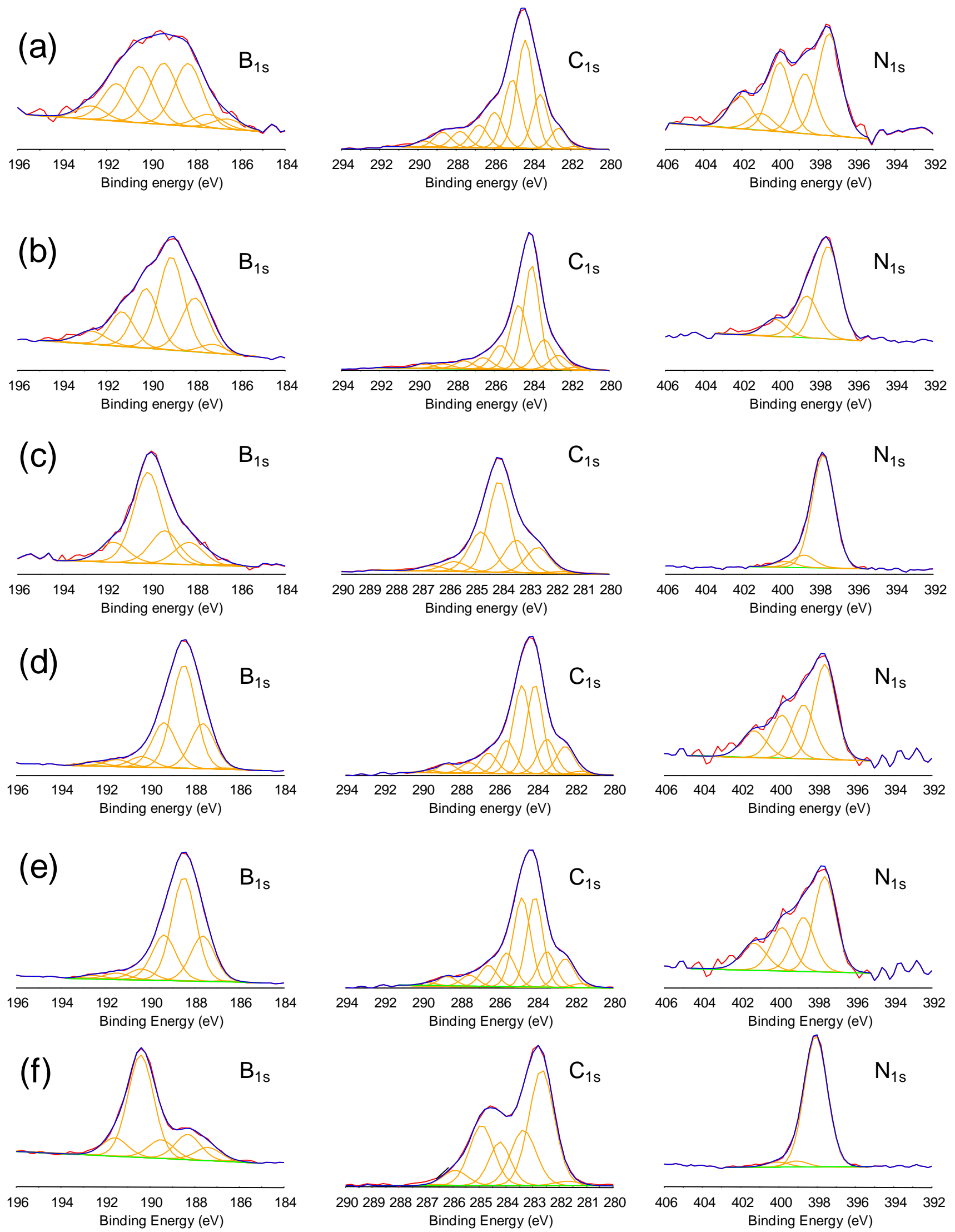

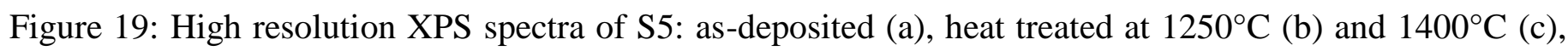
and S6: as-deposited (d), heat treated at $1250^{\circ} \mathrm{C}$ (e) and $1400^{\circ} \mathrm{C}$ (f) 
Surprisingly, the surface of S6 displays a high boron concentration compared to the bulk. The XPS analyses do not show significant changes in the chemical composition and the atomic bond distribution in S5 and S6 after heat treatment at $1250^{\circ} \mathrm{C}$. In contrast, the $1400^{\circ} \mathrm{C}$ treatment results in an important change of the atomic environment, as well as an unexpected contamination by silicon, especially in the case of S6 (table 8). This phenomenon was not due to silicon diffusion from the fibers but to contamination by residual silicon vapor in the furnace (a silicon melting test was performed just before the heat treatments to control the temperature). Further in-depth AES analyses indeed revealed that the silicon concentration was maximal at the extreme surface and dropped sharply inwards. Besides this silicon enrichment of the surface, the XPS spectra reveal a strong increase of the proportion of $B-N_{3}$ and $N-B_{3}$ environments (i.e. of h-BN) at the expense of the h-B-C and h-B-C-N characteristic sites (figure 19). The energy of the $N-B_{3}$ component is simultaneously shifted to a higher value $(\approx 398.0 \mathrm{eV})$ after the $1400^{\circ} \mathrm{C}$ annealing, which is more consistent with h-BN than the as-deposited value (table 7). The atomic proportions of the h-BN component extracted from both $B_{1 s}$ and $N_{1 s}$ spectra, were found reasonably close for both S5-1400 and S6-1400 samples (compare 8.6 at.\% at $190.2 \mathrm{eV}$ to 9.9 at.\% at $397.7 \mathrm{eV}$ and 9 at.\% at $190.4 \mathrm{eV}$ to 11.2 at.\% at $398.1 \mathrm{eV}$, respectively for S5-1400 and S6-1400). Such a $\mathrm{B}_{1 \mathrm{~s}} / \mathrm{N}_{1 \mathrm{~s}}$ ratio found in visible presence of the h-BN phase, strengthen the XPS single component assignations proposed in section 3.3.3. Carbon is for the most part $\mathrm{sp}^{2}$ except for S6-1400 ${ }^{\circ} \mathrm{C}$, due to the formation of carbide C-Si bonds. Even if there is still some doubt about the effect of the silicon contamination, a phase demixing may have occurred in the $\mathrm{B}_{\mathrm{x}} \mathrm{C}_{\mathrm{y}} \mathrm{N}_{\mathrm{z}}$ coatings leading to $\mathrm{h}-\mathrm{BN}$ and h-C carbon domains arranged at the nanometer scale. A similar phenomenon was noticed for B-N$\mathrm{C}$ heterostructures deposited on $\mathrm{Pt}(111)$ surfaces from dimethylamine borane [84-85]. In this case of a B-N$\mathrm{C}$ monolayer form, the phase separation into graphite and hexagonal $\mathrm{BN}$ was observed after annealing beyond a temperature as low as $727^{\circ} \mathrm{C}$.

\subsection{Mechanical properties of $\mathrm{SiC} / \mathrm{B}_{\mathrm{x}} \mathrm{C}_{\mathrm{y}} \mathrm{N}_{\mathrm{z}} / \mathrm{SiC}$ composites}

\section{- $\quad 3.5 .1$ Tensile tests at room temperature}

The four $\mathrm{B}_{\mathrm{x}} \mathrm{C}_{\mathrm{y}} \mathrm{N}_{\mathrm{z}}$ interphases introduced in the $1 \mathrm{D}$ model composites correspond to the $\mathrm{S} 1$ to $\mathrm{S} 4$ coatings that have been characterized in details in the previous sections. The mechanical behavior of these four types of microcomposites was compared to that of a reference material prepared with a $150 \mathrm{~nm}$-thick pyrolytic carbon interphase.

The stress-strain curves recorded during the tensile tests reveal a typical damageable elastic behavior that can be attributed to matrix cracking and crack deviation at fiber/matrix interface [56] (figure 20). 


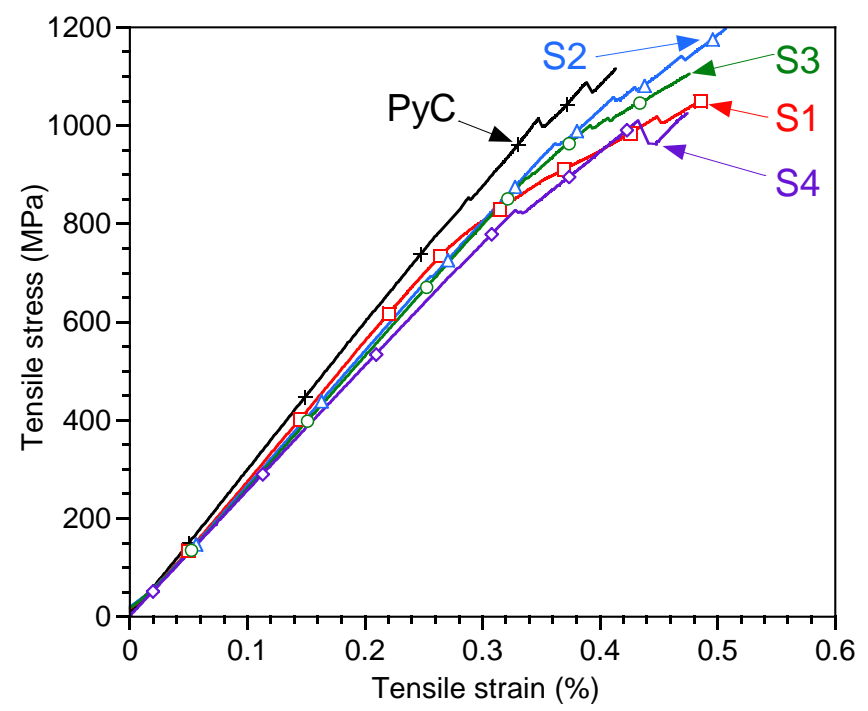

Figure 20: Typical tensile behavior of $\mathrm{SiC} / \mathrm{SiC}$ microcomposites prepared with of pyrocarbon and $\mathrm{B}_{\mathrm{x}} \mathrm{C}_{\mathrm{y}} \mathrm{N}_{\mathrm{z}}$ interphases.

As shown in table 10, the composites with a carbon-rich $\mathrm{B}_{\mathrm{x}} \mathrm{C}_{\mathrm{y}} \mathrm{N}_{\mathrm{z}}$ interphase and more especially $\mathrm{S} 2$, display slightly higher strain to failure values. SEM observations and local AES analyses evidenced that failure occurred almost every time at the interface between the fiber and the interphase, for the B- and N-rich $\mathrm{B}_{\mathrm{x}} \mathrm{C}_{\mathrm{y}} \mathrm{N}_{\mathrm{z}}$ coatings having a low anisotropy ( $\mathrm{S} 3$ and $\mathrm{S} 4$ ). On the other hand, two different decohesion modes are observed in the composite with a S1 interphase, either at fiber-interphase or interphase-matrix interfaces. The occurrence of cracks propagating at both interfaces and probably also across the $\mathrm{B}_{\mathrm{x}} \mathrm{C}_{\mathrm{y}} \mathrm{N}_{\mathrm{z}}$ interphase, is an indication of a higher amount of dissipated energy. In contrast, decohesions take place only between interphase and matrix in sample S2. This particular type of damage better preserves the fiber surface from oxidation and is therefore expected to improve the life time in air of ceramic composites.

\begin{tabular}{|c|c|c|c|c|c|}
\hline & $\mathrm{E}(\mathrm{GPa})$ & $\sigma^{\mathrm{EL}}(\mathrm{MPa})$ & $\varepsilon^{\mathrm{EL}}(\%)$ & $\sigma^{\mathrm{F}}(\mathrm{MPa})$ & $\varepsilon^{\mathrm{F}}(\%)$ \\
\hline PyC & $292 \pm 22$ & $830 \pm 185$ & $0,280 \pm 0,060$ & $1116 \pm 157$ & $0.413 \pm 0.075$ \\
\hline $\mathrm{S} 1$ & $279 \pm 24$ & $820 \pm 165$ & $0,290 \pm 0,045$ & $1058 \pm 136$ & $0.490 \pm 0.120$ \\
\hline $\mathrm{S} 2$ & $280 \pm 20$ & $915 \pm 150$ & $0,330 \pm 0,055$ & $1198 \pm 152$ & $0.507 \pm 0.100$ \\
\hline S3 & $258 \pm 29$ & $820 \pm 150$ & $0,310 \pm 0,070$ & $1105 \pm 850$ & $0.476 \pm 0.105$ \\
\hline S4 & $265 \pm 20$ & $770 \pm 220$ & $0,290 \pm 0,080$ & $1025 \pm 135$ & $0.474 \pm 0.090$ \\
\hline
\end{tabular}

Table 10: Tensile properties of $\mathrm{SiC} / \mathrm{SiC}$ microcomposites prepared with various $\mathrm{B}_{\mathrm{x}} \mathrm{C}_{\mathrm{y}} \mathrm{N}_{\mathrm{z}}$ interphases (E: Young's modulus, $\sigma^{\mathrm{EL}} / \varepsilon^{\mathrm{EL}}$ : elastic limit strength / strain, $\sigma^{\mathrm{F}} / \varepsilon^{\mathrm{F}}$ : ultimate failure strength / strain). 30 specimens of each type were tested with a gauge length of $10 \mathrm{~mm}$

\section{- 3.5.2 Static fatigue tests at $550^{\circ} \mathrm{C}$}

The lifetime in ambient air at $550^{\circ} \mathrm{C}$ of microcomposites prepared with a $\mathrm{S} 1$ type interphase, was compared to that of reference specimens with pyrocarbon interphase. The lifetime of the reference composites is highly dispersed, ranging from several min to several tens of hours. The mean value is estimated around $3 \mathrm{~h}$. 
Pyrolytic carbon is rapidly oxidized at $550^{\circ} \mathrm{C}$. After several hours at this temperature the charge transfer between matrix and fiber is no longer ensured, eventually causing the composite failure. However, post mortem SEM observation of the failure surface of the specimens revealed that the pyrocarbon interphase was not entirely consumed.

The lifetime of the microcomposites with $\mathrm{B}_{\mathrm{x}} \mathrm{C}_{\mathrm{y}} \mathrm{N}_{\mathrm{z}}$ interphase is remarkably different. None of them were broken after as long as $2000 \mathrm{~h}$ ageing, the maximum time duration of the tests.

The rapid oxidation of pyrocarbon during the static fatigue tests in ambient air at $550^{\circ} \mathrm{C}-$ and the shorter lifetime of the reference composite compared to the composites with a S1 interphase - seems to be in contradiction with Figure 17 illustrating that $\mathrm{B}_{\mathrm{x}} \mathrm{C}_{\mathrm{y}} \mathrm{N}_{\mathrm{z}}$ coatings oxidize faster than pyrocarbon. These two tests are in fact very different. During the oxidation test, the whole outer surface of the coating is exposed to ambient air while the material is stress free. In contrast in the lifetime test, the composite is loaded at a level that is supposed to exceed the effective yield strength. In this case only a very limited part of the interphase is exposed to oxidation through the crack network. Several other parameters than the sole oxidation behavior are therefore expected to influence the lifetime of the composite. These factors are mostly related to the failure of the matrix and the interfaces (interphase/matrix or fiber/interphase). Moreover, it cannot certain that the applied load always exceeded the effective yield strength during the lifetime tests. Of course if there is no cracking, the interphase will not be exposed to air and the lifetime (supposed to be asseesed under load after matrix cracking) overestimated.

\section{CONCLUSION}

The aim of the present work was to deposit hexagonal $\mathrm{B}_{\mathrm{x}} \mathrm{C}_{\mathrm{y}} \mathrm{N}_{\mathrm{z}}$ coatings by CVD and optimize their composition for a use as an interphase in ceramic matrix composites. The $\mathrm{BCl}_{3} / \mathrm{NH}_{3} / \mathrm{H}_{2}$ system was selected as the gas precursor because it has been already studied by several authors and shown to be highly reactive. In particular, a Lewis acid-base complex can be formed directly from the reaction between $\mathrm{NH}_{3}$ and $\mathrm{BCl}_{3}$, without any activation barrier. The resulting $\mathrm{Cl}_{3} \mathrm{~B}: \mathrm{NH}_{3}$ adduct is suspected to act as the first brick of a series of chloroborane precursors involved in the formation of boron nitride. As a matter of fact, the increase of the ammonia ratio in the initial gas phase results in a simultaneous enrichment of the deposit in boron and nitrogen, and not solely in nitrogen.

The structure of the deposits was not examined at the atomic scale, but XPS analyses and relevant works from the literature based on analyses of the local atomic structure and theoretical calculations, suggest that the $\mathrm{B}_{\mathrm{x}} \mathrm{C}_{\mathrm{y}} \mathrm{N}_{\mathrm{z}}$ coatings are probably not homogeneous solid solutions at the atomic scale. They more probably consist of nanometric hexagonal clusters of h-BN and an assembly of $\mathrm{sp}^{2}$-hybridized B-C and C-C bonds, which tend to segregate as the deposition temperature is raised.

From a preliminary study of the CVD process, a deposition temperature of $1050{ }^{\circ} \mathrm{C}$ was found to be a good compromise, i.e. high enough to promote a high anisotropy, as required for the use as an interphase, and low enough to preserve the mechanical properties of the fibers. A total pressure of $4 \mathrm{kPa}$ was found to provide an 
adequate set of deposition rate, elemental composition in the B-C-N ternary and thickness homogeneity of the deposits along the axis of the fiber substrate.

Using these $\mathrm{T}$ and $\mathrm{P}$ values, we investigated the influence of four initial compositions of the gas phase on the atomic concentration and the structural properties of coatings deposited on Nicalon fibers. $A B_{x} C_{y} N_{z}$ deposit with a composition close to $\mathrm{BC}_{3}$ was found to have a high cristallinity, leading to a particularly high oxidation resistance.

Under dry air, all the $\mathrm{B}_{\mathrm{x}} \mathrm{C}_{\mathrm{y}} \mathrm{N}_{\mathrm{z}}$ coatings have a far better resistance to oxidation than pyrolytic carbon. In contrast, pyrocarbon shows a better oxidation resistance in wet atmosphere. In presence of moisture, the $\mathrm{B}_{\mathrm{x}} \mathrm{C}_{\mathrm{y}} \mathrm{N}_{\mathrm{z}}$ coatings are no longer protected from oxidation by the formation of $\mathrm{B}_{2} \mathrm{O}_{3}$, due to its reaction with water vapor leading to reactive vaporization. We also investigated the influence of the deposition temperature and post-deposition heat treatment, on the oxidation resistance of the $\mathrm{B}_{\mathrm{x}} \mathrm{C}_{\mathrm{y}} \mathrm{N}_{\mathrm{z}}$ coatings. As expected, a high deposition temperature improves the structural organization of the deposit and increases the oxidation resistance. A high temperature post-deposition treatment was also found to raise the resistance against oxidation, though no significant structural change was detected by XRD. XPS analyses revealed that a temperature treatment as high as $1400^{\circ} \mathrm{C}$ increases the amount of boron nitride in the coating. Such an alteration of the composition results from the start of decomposition of the $\mathrm{B}_{\mathrm{x}} \mathrm{C}_{\mathrm{y}} \mathrm{N}_{\mathrm{z}}$ material.

Tensile tests carried out on microcomposites showed that $\mathrm{CMC}$ prepared with a $\mathrm{B}_{\mathrm{x}} \mathrm{C}_{\mathrm{y}} \mathrm{N}_{\mathrm{z}}$ interphase display a damageable elastic behavior similar to that of standard pyrocarbon-based CMC.

Finally, we compared the lifetime at $550^{\circ} \mathrm{C}$ in ambient air of microcomposites prepared either with a pyrolytic carbon or a $\mathrm{B}_{\mathrm{x}} \mathrm{C}_{\mathrm{y}} \mathrm{N}_{\mathrm{z}}$ interphase. To expose more efficiently the interphase to oxidation, the tests were carried out under a constant stress 10 to $15 \%$ higher than the yield strength of the microcomposite to induce matrix cracking. Though highly dispersed, the mean lifetime was estimated around $3 \mathrm{~h}$ in the case of pyrocarbon interphases. In contrast, none of the $\mathrm{B}_{\mathrm{x}} \mathrm{C}_{\mathrm{y}} \mathrm{N}_{\mathrm{z}}$-based specimens were broken at the interruption of the test after $2000 \mathrm{~h}$. Though remarkable, such a behavior cannot be definitely attributed to the nature of the interphase. The load applied to the microcomposites with a $\mathrm{B}_{\mathrm{x}} \mathrm{C}_{\mathrm{y}} \mathrm{N}_{\mathrm{z}}$ interphase was indeed not statistically certain to exceed their affective yield strength.

One cannot objectively assert that a $\mathrm{B}_{\mathrm{x}} \mathrm{C}_{\mathrm{y}} \mathrm{N}_{\mathrm{z}}$ interphase improves the high temperature behavior of $\mathrm{SiC} / \mathrm{SiC}$ composites. The mechanical behavior of $\mathrm{SiC} / \mathrm{B}_{\mathrm{x}} \mathrm{C}_{\mathrm{y}} \mathrm{N}_{\mathrm{z}} / \mathrm{SiC}$ composites is similar to that of $\mathrm{SiC} / \mathrm{PyC} / \mathrm{SiC}$ composites but, more importantly, the oxidation resistance at medium temperature is much lower in presence of water vapor. As a perspective, it would be attractive to compare the behaviors of $\mathrm{SiC} / \mathrm{SiC}$ composites with $\mathrm{B}_{\mathrm{x}} \mathrm{C}_{\mathrm{y}} \mathrm{N}_{\mathrm{z}}$, h-B-C or $\mathrm{BN}$ interphases, especially around $550^{\circ} \mathrm{C}$ in moisture. Due to the mixed conclusions of the oxidation tests of the of $\mathrm{B}_{\mathrm{x}} \mathrm{C}_{\mathrm{y}} \mathrm{N}_{\mathrm{z}}$ interphase and the obvious difficulty to implement the $\mathrm{BCl}_{3} / \mathrm{NH}_{3} / \mathrm{H}_{2}$ gas system at large scale, $\mathrm{BN}$, h-B-C or even pyrocarbon may remain interphases of choice for a long-term use of CMC.

\section{REFERENCES}


[1] Kosolapova TYa, Makarenko GN, Serebryakova TI, Prilutskij EV, Khorpyakov OT, Chernysheva OI, Nature of boron carbonitride I. Conditions of preparation of boron carbonitride. Soviet Powder Metallurgy and Metal Ceramics 1971;10(1):22-26

[2] Badzian AR, Appenheimer S, Niemyski T, Olkusnik E. Graphite-boron nitride solid solutions by chemical vapor deposition, Proceedings of the Third International Conference on Chemical Vapor Deposition, Salt Lake City, UT, 1972. Edited by F.A. Glaski. American Nuclear Society, Hinsdale, IL, 1972;3:747-753

[3] Chen SH, Diefendorf RJ. Electrical properties of the system: Boron-Nitrogen-Carbon, Proceedings of the Third International Carbon Conference, Baden-Baden, FRG, 1980; p.45-46

[4] Moore AW, Strong SL, Doll GL, Dresselhaus MS, Spain IL, Bowers CW et al. Properties and characterization of codeposited boron nitride and carbon materials, J Appl Phys 1989;65:5109-5118.

[5] Besmann TM. Chemical vapor deposition in the Boron-Carbon-Nitrogen System, J Am Ceram Soc 1990;73(8):2498-2501

[6] Morita M, Hanada T, Tsutsumi H, Matsuda Y, Kawaguchi M. Layered-structure BC2N as a negative electrode matrix for rechargeable lithium batteries, J Electrochem Soc 1992;139(5):1227-1230

[7] Flandrois S, Ottaviani B, Derré A, Tressaud A. Boron-substituted carbons and their intercalation compounds. J Phys Chem Solids 1996;57(6-8):741-744

[8] Maquin B, Derré A, Labrugère C, Trinquecoste M, Chadeyron P, Delhaès P. Submicronic powders containing carbon, boron and nitrogen: their preparation by chemical vapour deposition and their characterization, Carbon 2000;38:145-156

[9] Kawaguchi M, Kawashima T, Nakajima T. Syntheses and structures of new graphite-like materials of composition $\mathrm{BCN}(\mathrm{H})$ and $\mathrm{BC}_{3} \mathrm{~N}(\mathrm{H})$. Chem Mater 1996;8:1197-1201

[10] Kawano T, Kawaguchi M, Okamoto Y, Enomoto H, Bando H. Preparation of layered B/C/N thin films on nickel single crystal by LPCVD. Solid State Sciences 2002;4:1521-1527

[11] Prilutskii EV, Makarenko GN, Serebryakova TI. Vysokotemperatur Karbidy 1975:84-89

[12] Hubacek M, Sato T. Preparation and properties of a compound in B-C-N System. J solid state Chem 1995;114:258-264

[13] Komatsu T, Goto A. Synthesis and characterization of graphite-like B-C-N materials of composition $\mathrm{CN}_{\mathrm{x}}(\mathrm{BN})_{\mathrm{y}}(\mathrm{x}<1, \mathrm{y} \leq 1)$. J Mater Chem 2002;12:1288-1293

[14] Maya L. Semiconducting amorphous films containing carbon, nitrogen, and boron. J Electrochem Soc 1988;135(5):1278-1281

[15] Maya L. Harris LA, Pyrolytic deposition of carbon films containing nitrogen and/or boron. J Am Ceram Soc 1990;73(7):1912-1916

[16] Bill J. Riedel R. Boron carbide nitride derived from amine-boranes. Mat Res Soc Symp Proc 1992;271

[17] Andreev YG, Lundström T, Harris RK, Oh SW, Apperley DC, Thompson DP, On the nature of boroncarbon-nitrogen compounds synthesized from organic precursors, J Alloys Compd 1995;277:102-108 
[18] Sauter D. Weinmann M. Berger F. Lamparter P. Müller K. Aldinger F. X-ray and neutron scattering and solid state NMR investigations on precursor-derived B-C-N ceramics using isotopic substitution. Chem Mater 2002;14:2859-2870

[19] Montasser K, Hattori S, Morita S. Characterization of hard transparent B-C-N-H thin films formed by plasma chemical vapor deposition at room temperature. J Appl Phys 1985 ;58(8):3185-3189

[20] Yamada M, Makaishi M, Sugishima K. Improvements of stress controllability and radiation resistance by adding carbon to boron-nitride. J Electrochem Soc 1990;137(7):2242-2246

[21] Weber A, Bringmann U, Klages CP, Taube K, Döllein G, Meyer H et al. Plasma deposition of BN, BCN:H and Me-BCN:H films using N-trimethylborazine (Me=Ti, Nb). J Phys III France 1992;2:1391-1398 [22] Zhao XA, Ong CW, Ng YM, Chan KF, Tsang YC, Choy CL et al. Structure of ion-beam-deposited BC-N-O films and the role of oxygen. J Mater Sci let 1997;16:1910-1913

[23] Dinescu M, Perrone A, Caricato AP, Mirenghi L, Gerardi C, Ghica C et al. Boron Carbon Nitride Films Deposited by Sequential Pulses Laser Deposition. Appl Surf Sci 1998;692:127-129

[24] Perrone A, Caricato AP, Luches A, Dinescu M, Ghica C, Sandu V et al. Boron carbonitride films deposited by pulsed laser ablation. Appl Surf Sci 1998;133:239-242

[25] Teodorescu VS, Luches A, Dinu R, Zocco A, Ciobanu MF, Martino M et al. Influence of the substrate temperature on BCN films deposited by sequential pulsed laser deposition. Appl Phys A 1999;69:S667-S670 [26] Popov C, Ivanov B, Masseli K, Shanov V. Deposition of BCN films by laser ablation, laser Physics. 1998;8(1):280-284

[27] Kosinova KL, Rumyantsev YuM, Fainer NI, Maximovski EA, Kuznetsov FA. The structure study of boron carbonitride films obtained by use of trimethylamine borane complex. Nucl Instrum Methods Phys Res, Sect. A 2001;470:253-257

[28] Stanishevsky A, Li H, Badzian A, Badzian T, Drawl W, Khriachtchev L, McDaniel E. B-C-N coatings prepared by microwave chemical vapor deposition. Thin Solid Films 2001;398-399:270-274

[29] Ray SC, Tsai HM, Chiou JW, Jan JC, Kumar K, Pong WF et al. X-ray absorption studies of boroncarbon-nitrogen $\left(\mathrm{B}_{\mathrm{x}} \mathrm{C}_{\mathrm{y}} \mathrm{N}_{\mathrm{z}}\right)$ ternary alloys. Diamond Relat Mater 2004;13:1553-1557

[30] Ray SC, Tsai HM. Electronic and bonding structures of B-C-N thin films investigated by X-ray absorption and photoemission spectroscopy. J Appl Phys 2004;96(1):208-211

[31] Caretti I, Torres R, Gago R, Landa-Canovas AR, Jiménez I. Effect of carbon incorporation on the microstructure of $\mathrm{BCxN}(\mathrm{x}=0.25,1,4)$ ternary solid solutions studied by transmission electron microscopy. Chem Mater 2010;22:1949-1951

[32] Dietrich D, Roll U, Stöckel S, Weise K, Marx G. Structure and composition studies of chemical vapour-deposited BCN fibre coating. Anal Bioanal Chem 2002;374:712-714

[33] Stöckel S, Weise K, Thamm T, Körner KU, Dietrich D, Marx G. Comparative investigations of structure and properties of BCN coatings deposited by thermal and plasma-enhanced CVD. Anal Bioanal Chem 2003;375:884-890 
[34] Saugnac F, Teyssandier F, Marchand A. Characterization of C-B-N solid-solutions deposited from a gaseous-phase between 900-degrees-C and 1050-degrees-C. J Am Ceram Soc 1992;75:161-169

[35] Derré A, Filipozzi L, Bouyer F, Marchand A. Parametric study of the chemical vapour deposition of carbon-boron-nitrogen compounds, J Mater Sci 1994;29:1589-1594

DOI: $10.1007 / \mathrm{BF} 00368931$

[36] Enouz S, Stephan O, Cochon JL,| Christian C, Loiseau A. C-BN patterned single-walled nanotubes synthesized by laser vaporization. Nano Letters 2007;7(7):1856-1862

[37] Liu AY, Wentzcovitch RM, Cohen ML. Atomic arrangement and electronic structure of BC2N. Physical Review B 1989; 39(3):1760-1765

[38] Nozaki H, Itoh S. Structural stability of BC2N. J Phys Chem Solids 1996;57(1):41-49

[39] Blase X. Properties of composite $\mathrm{BxCyNz}$ nanotubes and related heterojunctions. Computational Materials Science 2000;17:107-114

[40] Ivanovskaya VV, Zobelli A, Stephan O, Briddon PR, Christian C. BN domains included into carbon nanotubes: role of interface. J Phys Chem C 2009;113:16603-16609

[41] Kouvetakis J, Kaner RB, Sattler ML, Bartlett N. A novel graphite-like material of composition $\mathrm{BC}_{3}$, and nitrogen-carbon graphites. J Chem Soc Chem Commun 1986;24:1758-1759

[42] Kaner RB, Kouvetakis J, Warble CE, Sattler ML, Bartlett N. Boron-carbon-nitrogen materials of graphite-like structure, Mat Res Bull 1987;22:399-404

[43] Kouvetakis J, Sasaki T, Shen C, Hagirawara R, Lerner M, Krishnan KM et al. Novel aspects of graphite intercalation by fluorine and fluorides and new $\mathrm{B} / \mathrm{C}, \mathrm{C} / \mathrm{N}$ and $\mathrm{B} / \mathrm{C} / \mathrm{N}$ materials based on the graphite network. Synthetic Metals 1989;34:1-9

[44] Derre A, Filipozzi L, Peron F. High temperature behaviour and oxidation resistance of carbon-boronnitrogen compounds obtained by LPCVD. Journal de Physique IV, Colloque C3, supplement au Journal de Physique II, Volume 31993

[45] Naslain R. Fibre-matrix interphases and interfaces in ceramic matrix composites processed by CVI. Composite Interfaces 1993;1(3):253-286

[46] Cermignani W, Paulson TE, Onneby C, Pantano CG. Synthesis and characterization of boron-doped carbons. Carbon 1995;33(4):367-374

[47] Jacques S, Guette A, Bourrat X, Langlais F, Guimon C, Labrugere C. LPCVD and characterization of boron-containing pyrocarbon materials. Carbon 1996;34(9):1135-1143

[48] Shirazaki T, Derré A, Ménétrier M, Tressaud A, Flandrois S. Synthesis and characterization of boronsubstituted carbons. Carbon 2000;38:1461-1467

[49] Saugnac F. PhD thesis N539 University of Bordeaux I (France), 1990

[50] McDaniel AH, Allendorf MD. Flow-tube investigation of the high-temperature reaction between $\mathrm{BCl} 3$ and NH3. J Phys Chem A 1998;102:7804-7812

[51] Reinhardt S, Gastreicha M, Marian CM. Reactions in the initial stage of the CVD of BN, a quantum chemical investigation. Phys Chem Chem Phys 2000;2:955-963 
[52] Saugnac F, Marchand A. Sur le mécanisme de dépôt en phase vapeur de composés carbone-bore-azote entre 800 et $1000^{\circ}$ C. C. R. Acad. Sci. Paris 1990;310(II):187-192

[53] Weisbecker P, Guette A. Thin Film preparation of C/C composites and CMC using the Broad Argon Ion Beam method. Proceedings of 17th international conference on composite materials, ICCM 17, Edinburgh 2009

[54] Cofer CG, Economy J. Oxidative and hydrolitic sta bility of boron nitride. A new approach to improving the oxidation resistance of carbonaceous structures. Carbon 1995;33(4):389-395

[55] Lamon J, Rebillat F, Evans AG, Microcomposite test procedure for evaluating the interface properties of ceramic matrix composites. J Am Ceram Soc 1995;78(2):401-405

[56] Jacques S., Guette A., Langlais F., Naslain R. C(B) materials as interphases in SiC/SiC model microcomposites. J. Mater. Sci. 1997;32(4):983-988

[57] Matsuda T, Nakae H, Irai T. Density and deposition rate of chemical-vapour-deposited boron nitride. J Mater Sci 1988;23(2): 509-514

[58] Berjonneau J, Chollon G, Langlais F. Deposition process of amorphous boron carbide from $\mathrm{CH} 4 / \mathrm{BCl}$ 3/H2 precursor. J Electrochem Soc 2006;153(12):C795-C800

[59] Vallerot JM, Bourrat X, Mouchon A, Chollon G. Quantitative structural and textural assessment of laminar pyrocarbons through Raman spectroscopy, electron diffraction and few other techniques. Carbon, 2006;44(9):1833-1844

[60] Le Gallet S, Rebillat F, Guette A, Bourrat X, Doux F. Influence of a multilayered matrix on the lifetime of SiC/BN/SiC minicomposites. J Mater Sci 2004;39(6):2089-2097

[61] Bourrat X, Trouvat B, Limousin G, Vignoles G, Doux F. Pyrocarbon anisotropy as measured by electron diffraction and polarized light. J Mater Res 2000;15(1):92-101

[62] Reznik B, Gerthsen D, Hüttinger KJ. Micro- and nanostructure of the carbon matrix of infiltrated carbon fiber felts. Carbon 2001;39(2):215-229

[63] Bourrat X, Fillion A, Naslain R, Chollon G, Brendlé M. Regenerative laminar pyrocarbon. Carbon $2002 ; 40(15): 2931-2945$

[64] Chollon G. Structural and textural analyses of SiC-based and carbon CVD coatings by Raman Microspectroscopy. Thin Solid Films 2007;516(2-4):388-396

[65] Reznik B, Hüttinger KJ. On the terminology for pyrolytic carbon. Carbon 2002;40:617-636

[66] Bourrat X, Langlais F, Chollon G, Vignoles GL. Low temperature pyrocarbons: a review. J Braz Chem Soc 2006;17(6):1090-1095

[67] Farbos B, Weisbecker P, Fischer HE, Da Costa JP, Lalanne M, Chollon G et al. Nanoscale structure and texture of highly anisotropic pyrocarbons revisited with transmission electron microscopy, image processing, neutron diffraction and atomistic modeling. Carbon 2014;80:472-489

[68] Le Gallet S, Chollon G, Rebillat F, Guette A, Bourrat X, Naslain R et al. Microstructural and microtextural investigations of boron nitride deposited from $\mathrm{BCl}_{3}-\mathrm{NH}_{3}-\mathrm{H}_{2}$ gas mixtures. J. Europ. Ceram. Soc. $2004 ; 24: 33-44$ 
[69] Jin C, Kim J, Suh J, Shi Z, Chen B, Fan X et al. Interlayer electron-phonon coupling in WSe $2 / \mathrm{hBN}$ heterostructures. Nature Phys. 2017;13:127-131

[70] Kurmaev EZ, Ezhov AV, Shamin SN, Cherkashenko VM, Andreev YuG, Lundström T X-ray emission spectra and structural models of BCN materials. J Alloys Compd 1997;248(1-2):86-89

[71] Jones LE, Thrower PA. Influence of boron on carbon fiber microstructure, physical properties, and oxidation behavior. Carbon 1991;29(2):251-269

[72] Ottaviani B, Derré A, Grivei E, Mahmoud OAM, Guimon MF, Flandrois S et al. Boronated carbons: structural characterization and low temperature physical properties of disordered solids. J Mater Chem 1998;8(1):197-203

[73] Filipozzi L, Derré A, Conard J, Piraux L, Marchand A. Local order and electrical properties of boron carbonitride films. Carbon 1995;33(12);1747-1757

[74] Oliveira MN, Botelho Do Rego AM, Conde O. XPS investigation of $\mathrm{B}_{\mathrm{x}} \mathrm{N}_{\mathrm{y}} \mathrm{C}_{\mathrm{z}}$ coatings deposited by laser assisted chemical vapour desposition. Surf Coat Tech 1998;100-101(1-3);398-403

[75] Morjan I, Conde O, Oliveira M, Vasiliu F. Structural characterization of $\mathrm{CxByNz}(\mathrm{x}=0.1$ to $\mathrm{x}=0.2)$ layers obtained by laser-driven synthesis. Thin Solid Films 1999;340(1):95-105

[76] Tsai P-C. The deposition and characterization of BCN films by cathodic arc plasma evaporation. Surf Coat Tech, 2007;201(9-11):5108-5113

[77] Cholet V, Vandenbulcke L, Rouan JP, Baillif P, Erre R. Characterization of boron nitride films deposited from $\mathrm{BCl}_{3}-\mathrm{NH}_{3}-\mathrm{H}_{2}$ mixtures in chemical vapour infiltration conditions. J Mater Sci 1994;19:14171435

[78] Azevedo S, De Paiva R. Structural stability and electronic properties of carbon-boron nitride compounds. Europhys Lett 2006;75(1):126-132

[79] Ferro Y, Allouche A, Marinelli F, Brosset C. Theoretical study of oxygen adsorption on boron-doped graphite. Surface Science 2004;559(2-3):158-168

[80] Walker PL, Rusinko F, Austin LG. Gas reaction of carbon. Adv Catal 1959;11:133-221

[81] Bertran X, Labrugère C, Dourges MA, Rebillat F, Oxidation behavior of PAN-based carbon fibers and the effect on mechanical properties. Oxid Met 2013;80:1-11

[82] Jacobson N, Farmer S, Moore A, Sayir H. High-temperature oxidation of boron nitride: I, monolithic boron nitride. J Am Ceram Soc 1999;82(2):393-398

[83] Mah T, Hecht NL, McCullum DE, Hoenigman JR, Kim HM, Katz AP et al. Thermal stability of SiC fibres (Nicalon®). J Mater Sci 1984;19(4):1191-1201

[84] Nappini S, Píš I, Carraro G, Celasco E, Smerieri M, Savio L et al. On-surface synthesis of different boron-nitrogen-carbon heterostructures from dimethylamine borane. Carbon Available online 6 May 2017, doi: 10.1016/j.carbon.2017.05.026

[85] Nappini S, Píš I, Mentes TO, Sala A, Cattelan M, Agnoli S et al. Formation of a quasi-free-standing single layer of graphene and hexagonal boron nitride on $\mathrm{Pt}(111)$ by a single molecular precursor. Adv. Funct. Mater. 2016;26:1120-1126. 